\title{
Cell membrane disruption induced by amorphous silica nanoparticles in erythrocytes, lymphocytes, malignant melanocytes, and macrophages
}

\section{$\operatorname{AUTHOR}(\mathrm{S})$ :}

Shinto, Hiroyuki; Fukasawa, Tomonori; Yoshisue, Kosuke; Tezuka, Mikihito; Orita, Mayumi

\section{CITATION:}

Shinto, Hiroyuki ...[et al]. Cell membrane disruption induced by amorphous silica nanoparticles in erythrocytes, lymphocytes, malignant melanocytes, and macrophages. Advanced Powder Technology 2014, 25(6): 1872-1881

\section{ISSUE DATE:}

2014-11

URL:

http://hdl.handle.net/2433/196070

\section{RIGHT:}

(c) 2014 The Society of Powder Technology Japan. NOTICE: this is the author's version of a work that was accepted for publication in Advanced Powder Technology. Changes resulting from the publishing process, such as peer review, editing, corrections, structural formatting, and other quality control mechanisms may not be reflected in this document. Changes may have been made to this work since it was submitted for publication. A definitive version was subsequently published in Advanced Powder Technology, 25_6(2014) doi:10.1016/j.apt.2014.09.002; This is not the published version. Please cite only the published version.; この論文は出版社版でありません。引用の際には出版社版 をご確認ご利用ください。 


\section{Cell membrane disruption induced by amorphous silica}

\section{nanoparticles in erythrocytes, lymphocytes, malignant}

\section{melanocytes, and macrophages}

Hiroyuki Shinto, ${ }^{\dagger, *}$ Tomonori Fukasawa, Kosuke Yoshisue, Mikihito Tezuka, and Mayumi Orita

Department of Chemical Engineering, Kyoto University, Katsura, Nishikyo-ku, Kyoto 615-8510, Japan

${ }^{\dagger}$ Present address: Department of Chemical Engineering, Fukuoka University, 8-19-1 Nanakuma, Jonanku, Fukuoka 814-0180, Japan

* Author to whom correspondence should be addressed. Phone: +81-92-871-6631, Fax: +81-92-8656031, e-mail: hshinto@fukuoka-u.ac.jp 


\section{Abstract}

It is of critical importance to examine carefully the potential adverse effects of engineered nanoparticles (NPs) on human health and environments. In the present study, we have investigated the disruption of cell membranes induced by amorphous silica NPs in erythrocytes, lymphocytes (Jurkat), malignant melanocytes (B16F10), and macrophages (J774.1); these four types of mammalian cells have distinctive characteristics in terms of nucleated/non-nucleated cells, adherent/non-adherent cells, endocytosis, and phagocytosis. The silica-induced membranolysis was examined by exposing these different cells to serum-free culture media containing the amorphous silica NPs of different diameters (28, 50, 55, 156, and $461 \mathrm{~nm}$ ) under similar conditions. We investigated how the silica-induced membranolysis of the cells of different origins is influenced by the size and dose of the silica NPs. Additionally, the interaction forces of a silica microsphere with a living cell or a giant unilamellar vesicle composed of zwitterionic phosphatidylcholine lipids were measured by colloid-probe atomic force microcopy, whereby the affinities of silica surface for plasma membranes and protein-free phospholipid membranes were estimated. Possible mechanism of the silica-induced membranolysis was discussed.

Keywords:

Silica nanoparticles; Mammalian cells; Hemolysis; Cytotoxicity; Membrane disruption. 


\section{Introduction}

The recent advancement in nanotechnology enables us to produce a variety of functional nanoparticles (NPs) with unique physicochemical, optical, and/or electrical properties such as large specific surface area, high reactivity, tuned photoluminescence, and high electric conductivity, which differ from those of bulk materials of the same composition. The increasing use of these NPs in commercial and consumer products has given rise to heightened concern for their biological activity and environmental impact. It is therefore of critical importance to address the potential adverse effects of NPs on human health and environments.

In spite of the very simple chemical formula of silicon dioxide $\left(\mathrm{SiO}_{2}\right)$, silica exists in a very large number of different forms, which are characterized by crystallinities and specific physicochemical surface properties [1]. Since silica is a common mineral found naturally in sand and rock, silica exposure is usual in lots of occupations such as mines and quarries, where inhalation of crystalline silica dusts causes a lung disease (silicosis) [2-4]. Recently, the amorphous silica NPs possessing uniform size and shape as well as the nonspherical morphologies and/or the mesoporous structures have been produced for industrial and biomedical applications [5-9]. For this reason, the effects of silica on human health should be still extensively investigated in vitro and in vivo [10-12].

The impacts of silica on red blood cells (RBCs) have been investigated; consequently, the silica particles are found to exhibit hemolytic activity against washed RBCs in serum-free buffered saline within a few fours $[13,14]$, where the hemolytic activity is indicative of the degree of membrane damage. The hemolytic activity of silica varies according to the structural forms of silica such as crystallinity [15] and porosity [5-9], and is significantly reduced by (pre)treatment of the silica particle surfaces with serum $[13,16,17]$, some proteins [16-19], or some chemicals $[5-7,14,16,17,20-22]$. Nonetheless, the hemolytic activity of amorphous silica NPs with uniform size and shape other than crystalline silica dusts remains to be explored $[7,23]$.

In addition to the hemolytic activity, the cytotoxic effects of silica NPs on various types of cell lines 
and primary cells (originated from different kinds of tissues and organs) have been examined in terms of various cellular responses such as disruption of cell membrane, viability of cells, inhibition of cell growth, transformation, and release of various factors (e.g. cytokines): the target cells include lymphocytes [24], macrophages [25-31], epithelial cells [28,32-37], endothelial cells [27,38-40], mesothelial cells [41], keratinocytes [33,42], fibroblasts [34,37], neuroblasts [24,36], hepatic cells [43], myoblasts [44], and kidney cells [45]. The testing strategy and the treatment conditions vary study by study, because the robust methodology has not been established for assessing the cytotoxicity of NPs. Indeed, the cytotoxicity outcome of NPs is influenced by assay conditions, such as the addition of serum or surfactants [28,37] and the procedure/medium for rinsing the cell surfaces before exposure to NPs (according to our experience): the former alters the surface properties of NPs and cells, and the latter determines whether the serum proteins added in the culture medium and/or the extracellular proteins secreted by cells are efficiently removed from the cell surfaces or not. For these reasons, reliable in vitro studies must contain the detailed information of the assay conditions, which generates consistent toxicity data on NPs. Unfortunately, many of the reported studies lack of such information; this is the case for the cytotoxicity studies of silica NPs.

Our main focus of the present study is placed on the rupture of cell membrane caused by amorphous silica NPs, which is considered as a short-time cellular response to high-dose silica NPs [46]. We have examined this silica-induced membranolysis by exposing four different types of mammalian cells to serum-free media containing the amorphous silica NPs of different diameters (28, 50, 55, 156, and 461 $\mathrm{nm}$ ) under similar conditions, whereby the results of membranolysis for the different types of cells can be compared with each other. The target cells include erythrocytes (rabbit RBCs) as well as three cell lines of Jurkat (T lymphocytes), B16F10 (malignant melanocytes), and J774.1 (macrophages); the characteristics of these four types of cells significantly differ from each other, as summarized in Table 1. We have investigated how the silica-induced membranolysis of these cells of different origins is influenced by the size and dose of the silica NPs. In order to estimate the affinity of silica surface for plasma membranes, we have measured the interaction forces of a silica microsphere with a living cell or 
a giant unilamellar vesicle (GUV) composed of zwitterionic phosphatidylcholine lipids, using colloidprobe atomic force microcopy (AFM).

\section{Materials and methods}

\subsection{Reagents and culture media}

Culture media of RPMI 1640 (11875-093), phenol-red-free RPMI 1640 (11835-030), DMEM (21063029, Dulbecco's modified Eagle medium with 25-mM D-glucose, 4-mM L-glutamine, and 25.03-mM HEPES buffer, without sodium pyruvate or phenol red), and DPBS (14190-094, Dulbecco's phosphatebuffered saline without calcium or magnesium) were purchased from Life Technologies (Carlsbad, CA, USA), and MEM (05900, Eagle’s minimum essential medium with kanamycin, without L-glutamine or sodium bicarbonate) was from Nissui Pharmaceutical (Tokyo, Japan). Sodium chloride ( $\mathrm{NaCl}$ ), Lglutamine, and sodium bicarbonate were purchased from Nacalai Tesque (Kyoto, Japan). Fetal bovine serum (FBS; JRH Biosciences, Lenexa, KS, USA) was heat-inactivated in prior to use. 1,2-dioleoyl-snglycero-3-phosphocholine (DOPC) in chloroform $(25 \mathrm{mg} / \mathrm{mL}=31.8 \mathrm{mM})$ was purchased from Avanti Polar Lipids (Alabaster, AL, USA). Chloroform, acetone, ethanol (Kishida Chemical, Osaka, Japan), and methanol (Sigma-Aldrich, St. Louis, MO, USA) were used without further treatment: these reagents were of analytical grades. All water used in the experiments was purified using a system composed of Elix Advantage 3 (Millipore, Billerica, MA, USA) and WR600A (Yamato Scientific, Tokyo, Japan) to give a resistance of $18.2 \mathrm{M} \Omega \mathrm{cm}$ and a total organic carbon of less than $20 \mathrm{ppb}$.

\subsection{Red blood cells (RBCs)}

The red blood cells (RBCs) were collected from rabbit blood preserved in Alsever’s solution (0105-1; 
Nippon Biotest Laboratories, Tokyo, Japan). The RBCs were gently rinsed three times with DPBS through a series of centrifugation (at a gravitational field of $750 \mathrm{~g}$ for $5 \mathrm{~min}$ ), aspiration of the supernatant, and redispersion of the remained cell pellet. Consequently, the RBC suspension of $7.5 \times$ $10^{9}$ cells/mL was obtained.

\subsection{Cell lines and culture conditions}

The human lymphocyte cell line of Jurkat (JCRB0147; JCRB Cell Bank, Osaka, Japan) was cultured in a complete medium composed of an RPMI 1640 medium, a 1\% penicillin-streptomycin mixed solution (26253-84; Nacalai Tesque), and 10\% FBS. The murine melanoma cell line (B16F10; ATCC CRL-6475) was cultured in a complete medium composed of MEM, 2-mM L-glutamine, and 10\% FBS; additionally, sodium bicarbonate was used to adjust the $\mathrm{pH}$ to 7.4. The murine macrophage cell line of J774.1 (JCRB0018; JCRB Cell Bank) was cultured in a complete medium composed of an RPMI 1640 medium and 10\% FBS. The non-adherent (Jurkat) and the adherent (B16F10 and J774.1) cells were cultivated statically in a flask with nontreated surface (1110-075; IWAKI, Tokyo, Japan) and in a flask with tissue culture treated surface (3110-075; IWAKI), respectively; every flask had a culture area of 75 $\mathrm{cm}^{2}$ and contained $10 \mathrm{~mL}$ of the complete medium. These flasks were stored in an incubator, inside which a moist atmosphere of $5.0 \% \mathrm{CO}_{2}$ was kept at temperature of $37.0{ }^{\circ} \mathrm{C}$. This ensured that the complete medium maintained the physiological $\mathrm{pH}$ of 7.4. The complete medium for each cell line was changed every 2 days. The cells were subcultured every 4 days, when they were grown at the concentration of about $1.0 \times 10^{6}$ cells $/ \mathrm{mL}$ for Jurkat and at the surface density of $1.4 \times 10^{5}$ cells $/ \mathrm{cm}^{2}$ for B16F10 and $1.3 \times 10^{5}$ cells/cm² for J774.1.

\subsection{Zeta potentials of cells}

The electrophoretic mobility of the cells (RBC, Jurkat, B16F10, and J774.1) in 100-mM NaCl 
solution was measured at room temperature, using a homemade apparatus, where a rectangular silicaglass cell $(10-\mathrm{mm} \times 1$-mm cross section), a cell holder, and a pair of platinum electrodes for MicroElectrophoresis Apparatus Mark II (Rank Brothers, Cambridge, UK) were employed. Before the measurements, the cells were gently rinsed two times with $100-\mathrm{mM} \mathrm{NaCl}$ solution by a series of centrifugation, aspiration of the supernatant, and redispersion of the remained cell pellet. The zeta potential of the cells was calculated from the mean electrophoretic mobility using Smoluchowski’s equation.

\subsection{Nanoparticles (NPs)}

The green-fluorescent nonporous silica $\left(\mathrm{SiO}_{2}\right)$ NPs of unmodified surfaces and different diameters were purchased from micromod Partikeltechnologie (Rostock Warnemünde, Germany), as listed in Table 2. Every silica NP suspension was diluted with three different media depending on the cell lines: DPBS for RBCs, phenol-red-free RPMI 1640 for Jurkat and J774.1 cells, and DMEM for B16F10 cells. These solutions containing the NPs were prepared at desired concentrations and kept in sterile cryo tubes (89050; TPP Techno Plastic Products AG, Trasadingen, Switzerland). The NP-containing solutions were stocked in a refrigerator at $5{ }^{\circ} \mathrm{C}$ and used within a week after the preparation. Just prior to use for exposure of the cells to the NPs, the NP-containing solutions were warmed up at $37.0{ }^{\circ} \mathrm{C}$ using a water bath (NTT-2000; Tokyo Rikakikai, Tokyo, Japan) and then sonicated for 5 min using an ultrasonic cleaning bath 3510J-MT (oscillation frequency $42 \mathrm{kHz}$, acoustic energy $130 \mathrm{~W}$; Branson Ultrasonic, Danbury, CT, USA). Equal volumes of the sonicated NP-containing solutions were filled in 96-well cell culture plates including $100 \mu \mathrm{L}$ /well of the NP-free fresh medium, as will be explained in Section 2.6. Thus, FBS was never added into the NP-containing solutions throughout the experiments in the present study, whereby the effects of serum proteins were eliminated from the experimental results.

The NPs suspended in 1-mM NaCl solutions or DPBS at $25^{\circ} \mathrm{C}$ were characterized with respect of hydrodynamic diameters and zeta potentials, using Zetasizer Nano ZS (Malvern Instruments, 
Worcestershire, UK). In prior to the sample preparation, these liquid media were filtered using the surfactant-free cellulose acetate membranes with $0.2-\mu$ m pores (155-0020; Nalgene).

\subsection{Exposure of cells to NPs}

The RBC suspension prepared as in Section 2.2 was filled in a 96-well round-bottom plate with nontreated surface (3875-096; IWAKI) to satisfy the liquid volume of $100 \mu \mathrm{L} /$ well and the concentration of $1.5 \times 10^{9}$ cells/mL (i.e., $1.5 \times 10^{8}$ cells/well). Every well was then filled with $100 \mu \mathrm{L}$ of the NPcontaining DPBS solutions prepared as in Section 2.5. The NP concentrations of the final medium were $C_{\mathrm{NP}}=0,200,400,800$, and $1600 \mu \mathrm{g} / \mathrm{mL}$, whereas the RBC concentration was $7.5 \times 10^{8}$ cells $/ \mathrm{mL}(5.6 \%$ hematocrit). The samples were stored in the incubator at $37.0^{\circ} \mathrm{C}$ for the exposure period of $t_{\exp }=4 \mathrm{~h}$.

The Jurkat cells were seeded in a 96-well round-bottom plate with nontreated surface (3875-096; IWAKI). For this subculture, a 10-mL suspension of the cells grown in the $75-\mathrm{cm}^{2}$ flask prepared as in Section 2.3 were put into a 15-mL centrifuge tube (2325-015, IWAKI). The cells were rinsed with DPBS after centrifugation (at $750 \mathrm{~g}$ for $5 \mathrm{~min}$ ) and removal of the FBS-supplemented complete medium; subsequently, the cells were redispersed in phenol-red-free RPMI 1640 after centrifugation and removal of the DPBS, giving a cell suspension of $1.0 \times 10^{6}$ cells $/ \mathrm{mL}$. Proper amounts of this cell suspension and the NP-free fresh RPMI 1640 were filled in the 96-well plate to satisfy the liquid volume of $100 \mu \mathrm{L} /$ well and the concentration of $3.0 \times 10^{5}$ cells/mL (i.e., $3.0 \times 10^{4}$ cells/well). Every well was then filled with $100 \mu \mathrm{L}$ of the NP-containing RPMI 1640 solutions prepared as in Section 2.5. The NP concentrations of the final culture medium were $C_{\mathrm{NP}}=0,25,50,100$, and $200 \mu \mathrm{g} / \mathrm{mL}$, whereas the Jurkat concentration was $1.5 \times 10^{5}$ cells $/ \mathrm{mL}$. The samples were stored in the incubator at $37.0^{\circ} \mathrm{C}$ for $t_{\exp }=2 \mathrm{~h}$. Likewise, the cell samples at $C_{\mathrm{NP}}=0,1,2,10,20,100$, and $200 \mu \mathrm{g} / \mathrm{mL}$ were prepared and incubated for $t_{\exp }=24 \mathrm{~h}$.

The cells of B16F10 (or J774.1) were seeded in a 96-well flat-bottom plate with tissue culture treated surface (3860-096; IWAKI). For this subculture of B16F10 (J774.1), the $75-\mathrm{cm}^{2}$ flask with the 
subconfluent cells prepared as explained in Section 2.3 was rinsed once (twice) with 10-mL DPBS after removal of the FBS-supplemented complete medium; subsequently, the cells were separated from the base of the flask by trypsinization with a $1-\mathrm{mL}$ (2-mL) DPBS solution of $0.25 \%$ trypsin and $0.02 \%$ EDTA. A fresh 9-mL (18-mL) complete medium for B16F10 (J774.1) was then added into the flask, giving a $10-\mathrm{mL}(20-\mathrm{mL})$ cell suspension of $1.0 \times 10^{6}$ cells $/ \mathrm{mL}\left(5.0 \times 10^{5}\right.$ cells $\left./ \mathrm{mL}\right)$. Proper amounts of this cell suspension and the complete medium were filled in the 96-well plate to satisfy the concentration of $4.0 \times 10^{4}$ cells/cm² (i.e., $1.3 \times 10^{4}$ cells/well) for both B16F10 and J774.1. After 1-day incubation, the cell samples of B16F10 (J774.1) were rinsed once (twice) with DPBS after removal of the complete medium. After removal of DPBS, every well was filled with $100 \mu \mathrm{L}$ of the NP-free fresh culture medium (DMEM for B16F10 or phenol-red-free RPMI 1640 for J774.1), followed by addition of $100 \mu \mathrm{L}$ of the NP-containing culture medium prepared as in Section 2.5. The NP concentrations of the final culture medium were $C_{\mathrm{NP}}=0,200,400,800$, and $1600 \mu \mathrm{g} / \mathrm{mL}$. The samples were stored in the incubator at $37.0^{\circ} \mathrm{C}$ for $t_{\exp }=2 \mathrm{~h}$. Likewise, the cell samples at $C_{\mathrm{NP}}=0,8,16,80,160,800$, and 1600 $\mu \mathrm{g} / \mathrm{mL}$ were prepared and incubated for $t_{\exp }=24 \mathrm{~h}$.

\subsection{Hemolysis assay}

The 96-well plate prepared as in Section 2.6 had not only a $200-\mu \mathrm{L}$ DPBS containing NPs and RBCs in each well $\left(1.5 \times 10^{8}\right.$ cells/well), but also a $200-\mu \mathrm{L}$ DPBS without NPs or RBCs (for the background control) and a $200-\mu \mathrm{L}$ solution with hemolyzed RBCs prepared by mixing a $20-\mu \mathrm{L}$ cell suspension of $7.5 \times 10^{9}$ cells $/ \mathrm{mL}$ and a $180-\mu \mathrm{L}$ water (for the maximum hemoglobin release control). The 96-well plate was then centrifuged at $750 \mathrm{~g}$ for 5 min so that the RBCs suspended in the medium settled down. $100 \mu \mathrm{L}$ of the supernatant in each well was transferred to a 96-well clear plate with non-binding surface (3641; CORNING, Corning, NY, USA). Hemoglobin release in individual wells was recorded by an automated plate reader (Infinite M200; Tecan, Grödig, Austria) at a wavelength of 542 nm. Hemolysis 
was calculated by the formula:

$\%$ Hemolysis $=\frac{(\text { Hemoglobin release from treated RBCs })-(\text { Medium background })}{(\text { Maximum hemoglobin release })-(\text { Medium background })} 100$

Every sample was measured at least in triplicate.

\subsection{LDH and ATP assays}

LDH (lactate dehydrogenase) and ATP (adenosine triphosphate) assays were done using the CytoToxONE homogeneous membrane integrity assay and the CellTiter-Glo luminescent cell viability assay (Promega Corporation, Madison, WI, USA), respectively. The 96-well plates prepared as in Section 2.6 had not only a $200-\mu \mathrm{L}$ culture medium containing NPs and cells in each well, but also a 200- $\mu \mathrm{L}$ culture medium with cells (for the maximum LDH release control and the maximum ATP content control) and a $200-\mu \mathrm{L}$ medium without NPs or cells (for the background control). After incubation for desired exposure periods, $10 \mu \mathrm{L}$ of lysis solution (a $2.7 \% \mathrm{w} / \mathrm{v}$ solution of Triton X-100 in water) was added to the wells for the maximum LDH release control. The 96-well plates were then centrifuged at $750 \mathrm{~g}$ during 5 min for Jurkat or at 100 g during 3 min for B16F10 and J774.1, such that the cells suspended in the medium settled down.

For LDH assay, $100 \mu \mathrm{L}$ of the supernatant in each well was transferred to a 96-well black plate with non-binding surface (3650; CORNING). After being treated according to the manufacturer's instructions, the samples in individual wells were monitored by Infinite M200 with an excitation wavelength of 560 nm and an emission wavelength of $590 \mathrm{~nm}$. Cytotoxicity was calculated by the formula:

$\%$ LDH release $=\frac{(\text { LDH release from treated cells })-(\text { Culture medium background })}{(\text { Maximum LDH release })-(\text { Culture medium background })} \quad 100 \mathrm{I}$

For ATP assay, the 96-well plates with the remained contents of $100 \mu \mathrm{L} /$ well were equilibrated at $22 .{ }^{\circ} \mathrm{C}$ for 10 min using an incubator shaker for well plate (MBR-022UP; TAITEC, Saitama, Japan) and the equal volume $(100 \mu \mathrm{L})$ of the CellTiter-Glo reagent was then added to each well, according to 
the manufacturer's instructions. After additional 10-min shake/incubation for cell lysis and luminescence stabilization, $175 \mu \mathrm{L}$ of the mixture in each well was transferred to a 96-well white plate (3620-096; IWAKI) or a 96-well white plate with non-binding surface (3600; CORNING). The luminescence intensities from the samples in individual wells were recorded by Infinite M200 with an integration time of $1 \mathrm{~s}$ per well. Cell viability was calculated by the formula:

$\%$ ATP content $=\frac{(\text { ATP content inside treated cells })-(\text { Culture medium background })}{(\text { Maximum ATP content })-(\text { Culture medium background })}$ 100I

Every sample was measured at least in triplicate for LDH and ATP assays.

\subsection{Confocal laser scanning microscopy (CLSM)}

As for the non-adherent cells (RBC and Jurkat), a mixed suspension of the cells and the NPs was prepared as mentioned in Section 2.6, but was put in a 4-mL sterile culture tube (2235-012N; IWAKI) other than the 96-well plate. The final concentration of this mixture was $7.5 \times 10^{5}$ cells $/ \mathrm{mL}$ for RBC and $1.5 \times 10^{5}$ cells/mL for Jurkat. After incubation at $37.0^{\circ} \mathrm{C}, 1 \mathrm{~mL}$ of the mixture was the transferred to a sterile microtube, and the cells were gently rinsed two times with a fresh medium (DPBS for RBC and phenol-red-free RPMI 1640 for Jurkat) through a series of centrifugation (at $400 \mathrm{~g}$ for 5 min), aspiration of the supernatant, and redispersion of the remained cell pellet. A suspension of the rinsed cells was added into a $\phi$ 35-mm dish with $\phi$ 12-mm glass bottom (3911-035; IWAKI). On the other hand, the samples of the adherent cells (B16F10 and J774.1) for CLSM were prepared as described elsewhere [47]. The differential interference contrast (DIC) and the fluorescence images of the cell samples were obtained by CLSM (C1si-ready mounted on TE2000-E; Nikon, Tokyo, Japan) with the water-immersion objective $60 \times$ of N.A. $=1.20$ (VC60×WI; Nikon).

\subsection{Giant unilamellar vesicles (GUVs) and small unilamellar vesicles (SUVs)}


GUVs were prepared following Ref. [48]. Briefly, 60- $\mu$ L chloroform solution of DOPCs (31.8 mM) was admixed with a mixture of $940-\mu \mathrm{L}$ chloroform and $150-\mu \mathrm{L}$ methanol in a 50 -mL round-bottom evaporation flask. The aqueous phase (7 mL of water or DPBS) was then prudently added along the flask wall. This two-phase solution was left over $60 \mathrm{~min}$ at room temperature. The organic solvent was rotoevaporated for 5-10 min under reduced pressure (down to the final pressure $\approx 17 \mathrm{mbar}$ ) at $40{ }^{\circ} \mathrm{C}$ and 40 rpm, using a rotary evaporator (R-215, V-700, V-850, and B-491; BUCHI Labortechnik, Flawil, Switzerland) with a recirculating chiller (NCB-2500; Tokyo Rikakikai). During this rotoevaporation, two major boiling events were observed at the pressures of 450-380 mbar and 150-80 mbar, where chloroform and methanol mainly evaporated, respectively. The resulting aqueous solution (5.5-6 mL) was opalescent and contained GUVs with diameters ranging from 1 to $60 \mu \mathrm{m}$, as observed by light microscopy.

The prepared solution of GUVs was filtered, using a $\phi 25$-mm syringe filter of surfactant-free cellulose acetate membrane with $0.2-\mu \mathrm{m}$ pore (190-2520; Nalgene). The SUVs in the obtained solution were characterized in terms of hydrodynamic diameter and zeta potential, using Zetasizer Nano ZS.

\subsection{Atomic force microscopy (AFM) and colloid probes}

Before fabrication of colloid probes, the nonporous silica microspheres of typical $20-\mu \mathrm{m}$ diameter (Quartron SP-25B; FUSO CHEMICAL, Osaka, Japan) were thoroughly washed as follows. A powder of the silica microspheres was dispersed in a 10-mL Teflon FEP centrifuge tube containing ethanol at $50^{\circ} \mathrm{C}$. After 5-min stirring, the silica microspheres were washed three times with water. The collected microspheres were dispersed in a $5 \% \mathrm{H}_{2} \mathrm{O}_{2}$ aqueous solution at $50^{\circ} \mathrm{C}$. After 5 -min stirring and threetimes washing with water, the collected microspheres were dispersed in a 5-mM $\mathrm{NaOH}$ aqueous solution at room temperature. After 5-min stirring and three-times washing with water, the collected microspheres were dried in vacuum and stored in a clean tube. 
An AFM probe (OMCL-TR400PSA; Olympus, Tokyo, Japan), which has a V-shaped, 100- $\mu$ m long cantilever with a spring constant of the nominal value $0.08 \mathrm{~N} / \mathrm{m}$ and with an $\mathrm{Si}_{3} \mathrm{~N}_{4}$ pyramidal tip on its end, was rinsed with a series of acetone, ethanol, and water. The spring constant of every cantilever was calibrated by the thermal method and found to be $0.05-0.12 \mathrm{~N} / \mathrm{m}$. Out of the washed silica microspheres, a single microsphere of about $10-\mu \mathrm{m}$ diameter was selectively glued to the end of the cantilever $[49,50]$. Immediately prior to AFM measurements, the surfaces of the colloid probes were further cleaned by plasma treatment for $5 \mathrm{~min}$ in an argon-water moisture atmosphere at $5 \mathrm{~W}$, using a basic plasma kit (BP-1; SAMCO, Kyoto, Japan) combined with a 13.56-MHz radio frequency plasma generator (ENI ACG-3B).

An MFP-3D-BIO AFM system (Asylum Research, Santa Barbara, CA, USA) was used to measure the interaction forces between a silica surface of the colloid probe and a soft surface of a living cell or a GUV in the aqueous phase at room temperature in an air-conditioned laboratory $\left(23 \pm 2{ }^{\circ} \mathrm{C}\right)$. As for living cells (see Fig. 5a), the AFM measurements were carried out in the same way as described in Ref. [50], except for several conditions; in the present study, the glass-bottom dishes (GWSt-5040; WillCo Wells B.V., Amsterdam, the Netherlands) were used.

As for GUVs, three copper grids of 3-mm diameter and 15-20- $\mu \mathrm{m}$ thickness with DN300 square mesh (83- $\mu \mathrm{m}$ pitch, 45- $\mu \mathrm{m}$ hole width, 38- $\mu \mathrm{m}$ bar width; Okenshoji, Tokyo, Japan) were placed on a coverslip (35-mm round, No. 1S thickness; Matsunami Glass, Osaka, Japan) held by a fluid cell, and then $2 \mathrm{~mL}$ of the aqueous phase containing GUVs was added to the fluid cell; immediately prior to this use, the grids and coverslip were plasma-treated for $5 \mathrm{~min}$. The fluid cell was placed on the AFM base (the XY-scanner equipped with the manual XY-translation stage), under which an inverted light microscope was placed; this allowed us to check whether single GUVs were trapped in some individual holes of the grids or not. The cantilever with the colloid probe was fixed on the AFM head (the Zscanner) via the cantilever holder and immersed in the aqueous phase. Prior to the force measurements, the optical lever sensitivity was determined at the positions far from the grids, whereby the surface 
cleanliness of the colloid probe was checked at the same time. A GUV of $40-\mu \mathrm{m}$ diameter trapped in a grid's hole was selectively positioned right under the colloid probe, using the XY-translation stage (see Fig. 5b). Thus, we started the force measurements at Z-scan speed of $1.3 \mu \mathrm{m} / \mathrm{s}$, which was slow enough to eliminate the hydrodynamic effects.

\section{Results}

\subsection{Characterization of silica NPs, vesicles, and cells}

Table 2 summarizes the results of characterization of the silica NPs, the DOPC vesicles, and the cells employed in the present study. Every type of the NPs suspended in 1-mM NaCl solution exhibited the relatively small PDI (= 0.01-0.09) and the significantly large zeta potential in magnitude (= 35-73 mV). The Z-average diameter and PDI of the NPs in DPBS were almost the same as those in 1-mM $\mathrm{NaCl}$ solution, although the NPs in DPBS exhibited the small zeta potentials in magnitude (= 19-27 mV) compared with those in 1-mM NaCl solution. These results suggest that the silica NPs stably dispersed not only in 1-mM NaCl solution, but also in DPBS of a high ionic strength (150 mM) without significant aggregation. The culture medium of RPMI 1640 and DMEM had almost the same ionic strength $(\sim 140 \mathrm{mM})$ and the same $\mathrm{pH}(=7.0-7.4)$ as DPBS, indicating that the silica NPs listed in Table 2 stably dispersed in the culture medium of RPMI 1640 and DMEM as well.

The vesicles of zwitterionic DOPCs in water and DPBS had negatively charged surfaces: the latter exhibited the small zeta potentials in magnitude compared with the former. The cellular surfaces of RBC, Jurkat, B16F10, and J774.1 employed were negatively charged in an aqueous solution of physiological ionic strength. This is probably due to the presence of sialic acids and other negatively charged molecules. 
It is worth noting that the status of glycocalyx layer on the plasma membrane of mammalian cells could influence the cellular responses to particles, though it was not characterized in the present study. In addition, subcultured adherent cell lines often lack their intact glycocalyx layers due to the use of trypsin. Therefore, the subcultured adherent cells (B16F10 and J774.1) after trypsinization were preincubated in FBS-supplemented complete media for 1 day before exposure to NPs (see Sections 2.6 and 2.9) and the cell-microsphere interaction force measurements (see Section 2.11). Such pre-incubation allowed the adherent cells to recover their glycocalyx layers to some extent, which would diminish the impact of trypsinization on the adherent cells.

\subsection{Cytotoxicity and cell viability after 24-hours exposure to silica NPs}

Panels a-c of Fig. S1 display the cellular responses after 24-hours exposure to different silica NPs as a function of the NP mass dose for Jurkat, B16F10, and J774.1, respectively. It is noted that the population doubling times of these cell lines were about 20-30 hours in NP-free, FBS-supplemented culture media. In the case of 24-hours exposure of these mammalian cells to the NPs, the LDH release is associated with the cytotoxicity, whereas the ATP content is related to the cell viability. As shown in Fig. S1a for Jurkat, the cytotoxicity increased and the cell viability decreased as the NP mass dose of every type of the silica NPs increased up to a certain value, and then they became almost constant, indicating that the cytotoxicity and the cell viability were correlated with each other. The smaller NPs exhibited the higher cytotoxicity and the less viability. These dose- and size-dependent behaviors of cytotoxicity and cell viability were found in Fig. S1b for B16F10 and Fig. S1c for J774.1 as well. It is noted that the LDH release from Jurkat and J774.1 was not negligible even in the NP-free culture media, which would be a consequence resultant from living and proliferation of the cells. Similar behaviors of cytotoxicity and cell viability have been reported for endothelial cells [27,38], keratinocytes [42], and macrophages [25-27], where the cells were treated with silica NPs in serum-free media for 24 hours. 
Once the exposure dose was converted to the equivalent NP surface area per suspension volume, the results of cytotoxicity (or cell viability) for silica NPs of different sizes were apparently represented by a master curve, as shown in panels a-c of Fig. 1 for Jurkat, B16F10, and J774.1, respectively. A similar scaling behavior of the cellular responses to silica NPs in serum-free culture media has been reported for endothelial cells [38] and macrophages [26]. Henceforth, the NP surface area per suspension volume is referred to as the NP surface area dose in the present study.

\subsection{CLSM images of cells after exposure to silica NPs within a few hours}

Using CLSM, the cells were observed after being exposed to the silica NPs within a few hours. The typical CLSM images are displayed in Fig. 2. The non-adherent cells of Jurkat and RBC settled down onto the substrate (see panels a and d of Fig. 2), whereas the cells of B16F10 and J774.1 were strongly adhered on the substrate (see panels b and c of Fig. 2). It is noted that the nucleated cells (Jurkat, B16F10, and J774.1) have the outer surfaces with microvilli [49,51] or membrane wrinkles [52], whereas the surface of RBC does not exhibit such microstructures [53]; thus, the outer surfaces of the nucleated cells are rather rough compared with that of RBC. Regardless of cell types, the silica NPs were mainly observed near the plasma membranes, but rarely found in the cytoplasmic region as well as the nuclear region. Similar results for RBCs were reported by Zhao et al. [8], where porous silica NPs were employed instead of nonporous silica NPs.

\subsection{Membrane integrity and metabolic activity of cells after 2-hours exposure to silica NPs}

Panels a-c of Fig. S2 display the cellular responses after 2-hours exposure to different silica NPs as a function of the NP mass dose for Jurkat, B16F10, and J774.1, respectively. Because of the short-time exposure to the NPs, the LDH release is associated with the membrane integrity of cells, while the ATP content is related to the metabolic activity of cells. The dose- and size-dependent behaviors of LDH 
release and ATP content were observed for every cell line. The reverse correlation between these two cellular responses indicates that the membrane integrity and the metabolic activity of the cells after exposure to the silica NPs were correlated with each other. The smaller silica NPs exhibited the greater lytic ability, where the cell membrane was disrupted and ruptured within a few hours (see also panels a-c of Fig. 2).

After being replotted as a function of NP surface area dose, the results of LDH release (or ATP content) appeared to be represented by a master curve regardless of the NP diameter, as shown in panel a-c of Fig.3 for Jurkat, B16F10, and J774.1, respectively. Thus, a scaling behavior of the short-time cellular responses to high-dose silica NPs in serum-free culture media was observed for three different cell lines (Jurkat, B16F10, and J774.1) in a wide range of NP diameters (28-461 nm); nonetheless, the large silica NPs of 461-nm diameter exhibited no significant impact on the adherent cells of B16F10 and J774.1.

\subsection{Hemolysis by silica NPs}

Figure 4 displays the hemolysis by 4-hours exposure to different silica NPs. As shown in Fig. 4a, the hemolysis increased with NP mass dose of the silica NPs, and became more significant for the smaller NPs. Once the exposure dose was converted to the equivalent NP surface area per suspension volume as in Fig. 4b, the dose- and size- dependent hemolytic activities of the silica NPs seemed to be on a master curve regardless of the NP diameter in the range of 50-461 nm.

The very early study [13] reported that hemolysis does not occur with 3- or 4-nm silica NPs, but does occur with 5-nm NPs and the hemolytic activity increases with NP diameter ranging from 5 to $30 \mathrm{~nm}$. This size dependence is diametrically opposite to those of Ref. [7] for 24-263 nm and of Fig. 4a for 50-461 nm. The contradiction between these results could originate from the difference in the size ranges of the employed NPs, although it remains to be explored. 


\subsection{Surface forces between a silica microsphere and a living cell or a GUV}

In order to estimate the affinity of silica surface for plasma membranes, we performed the AFM measurements of the interaction forces between a 10- $\mu \mathrm{m}$ silica microsphere and a living B16F10 cell (see Fig. 5a) or a GUV composed of DOPCs (see Fig. 5b).

In Fig. 5c, the force curve for silica-cell interaction during compression displayed zero force at the distances longer than $\sim 2 \mu \mathrm{m}$. The repulsion at the distances shorter than $\sim 2 \mu \mathrm{m}$ probably originated from both steric stabilization forces and viscoelastic forces; the former are caused by the compression of a dense lawn of microvilli on the cell surface [49] as well as a hydrated layer of long-chain polymer molecules (proteins and carbohydrates) thereon, while the latter result from the viscoelastic property of a cell [54]. After compression, the decompression force curve, which is the result of detachment of a microsphere from the apical surface of a cell, showed an initial de-adhesion peak at the distance of $\sim 1$ $\mu \mathrm{m}$ followed by several small steps of $20-40 \mathrm{pN}$, indicating that the silica surface adhered onto the apical membrane of the B16F10 cell. The small steps are attributable to the breaking of the multiple bonds formed at different locations of close contact between the cell and silica surfaces.

By contrast, both the compression and decompression force curves for silica-GUV interaction in DPBS were entirely repulsive, as shown in Fig. 5d. Similar results were obtained in water (data not shown). The repulsion at the distances shorter than $\sim 1.2 \mu \mathrm{m}$ was mainly originated from elastic property of a GUV.

\section{Discussion}

RBC, Jurkat, B16F10, and J774.1 were employed as target cells for amorphous silica NPs of different 
diameters (28, 50, 55, 156, and $461 \mathrm{~nm}$ ). These four types of mammalian cells have distinctive characteristics in terms of nucleated/non-nucleated cells, adherent/non-adherent cells, endocytosis, and phagocytosis, as summarized in Table 1. Despite of the fundamental differences among them, these cells had some similarities in their short-time responses to high-dose silica NPs in serum-free culture media, as shown in Figs. 2-4: (i) the silica NPs strongly adhered onto the cell membrane to disrupt and rupture it, (ii) this silica-induced membranolysis occurred within a few hours and increased with decreasing NP diameter and increasing NP mass dose, and (iii) the size- and dose-dependent membranolytic activity of the silica NPs appeared to be represented by a master curve as a function of the NP surface area per suspension volume regardless of the NP diameter. After 24-hours exposure to silica NPs, the nucleated cells of Jurkat, B16F10, and J774.1 responded, as shown in Fig. 1: (i) the cytotoxicity increased and the cell viability decreased with decreasing NP diameter and increasing NP mass dose, and (ii) the size- and dose-dependent cellular responses were apparently represented by a master curve as a function of the NP surface area per suspension volume regardless of the NP diameter. The cellular response after a-fewhours exposure reflected that after 24-hours exposure, although the latter was a consequence resultant from complex cellular behaviors such as adhesion/uptake of silica NPs onto/into cells, silica-induced membranolysis, recovery of the damaged cells, and proliferation of the survived cells. The scaling behaviors of Figs. 3 and $4 \mathrm{~b}$ as well as the CLSM images of Fig. 2 suggest that the membranolytic ability of silica NPs is related to the surface density and distribution of the negatively charged silanol (Si-OH) groups that are accessible to the cell membrane, irrespective of mammalian cell types. This is supported by the finding in Refs. [5,6]: the hemolytic activity of the porous silica NPs and the surface-modified silica NPs is considerably reduced compared to that of the nonporous bare silica NPs.

As shown in Table 2, the silica NPs, the DOPC vesicles, and the mammalian cells had the negatively charged surfaces on average in aqueous solutions of physiological ionic strength; indeed, the net interaction force between the silica and cell surfaces was not attractive or adhesive until they came into closer contact with each other, as shown in Fig. 5c. Considering the adhesive forces between them during decompression shown in Fig. 5c and the nature of cell membrane [55], however, it has been 
postulated that membranolysis of mammalian cells is originated by strong adsorption of membrane components onto the surface of silica NPs. The cell membrane is composed of a phospholipid bilayer with incorporated cholesterol and embedded proteins. Phospholipids consist of two long hydrophobic hydrocarbon chains attached to a hydrophilic polar head group. The head group contains of a negatively charged phosphate moiety and, often, a primary or quaternary amine moiety. It is noted that a major constituent of cell membranes is phosphatidylcholine (PC), which has a zwitterionic head group of the phosphate ester $\left(-\mathrm{R}\left(\mathrm{PO}_{4}^{-}\right) \mathrm{R}^{\prime}-\right)$ and the quaternary amine $\left(-\mathrm{N}\left(\mathrm{CH}_{3}\right)_{3}{ }^{+}\right)$moieties and is more commonly found in the exoplasmic leaflet of a cell membrane.

The interactions of silica particles with protein-free bilayers of PC have been investigated by the leakage of entrapped tracers from liposomes [56-58], the adsorption isotherms [57-62], the nuclear magnetic resonance (NMR) spectroscopy [63], the cryogenic transmission electron microscopy (CryoTEM) [64], the fluorescence microscopy and isothermal titration calorimetry [65], and the calorimetry, electrophoresis, dynamic light scattering (DLS), and Cryo-TEM [66,67]. The interactions of silica particles with supported membranes of PC have been studied by the electrochemistry and calorimetry [68] and the electrophysiology and fluorescence microscopy [69]. In addition to the particulate silica, the interactions of silica substrates with PC liposomes [70] have been studied by quartz crystal microbalance (QCM) [71-73] and AFM [62,74]. These studies indicate that affinity of the bare silica surface for neutral PCs is rather weak and mainly attributed to van der Waals forces [58-62,68], which is consistent with the results of our AFM measurements shown in Fig. 5d. Consequently, it is most likely assumed that the exoplasmic portions of membrane proteins are strongly adsorbed onto the surfaces of silica NPs, leading to membranolysis of mammalian cells.

\section{Conclusions}

Four types of mammalian cells (RBC, Jurkat, B16F10, and J774.1) were employed as target cells for 
amorphous silica NPs of different diameters (28, 50, 55, 156, and $461 \mathrm{~nm}$ ). These different cells had some similarities in their short-time responses to high-dose silica NPs in serum-free culture media: (i) the silica NPs strongly adhered onto the cell membrane to disrupt and rupture it, (ii) this silica-induced membranolysis occurred within a few hours and increased with decreasing NP diameter and increasing NP mass dose, and (iii) the size- and dose-dependent membranolytic activity of the silica NPs appeared to be represented by a master curve as a function of the NP surface area per suspension volume regardless of the NP diameter. The results of our AFM measurements shown in Fig. 5 imply that the exoplasmic portions of membrane proteins are strongly adsorbed onto the surfaces of silica particles, which leads to membranolysis of mammalian cells.

It should be noted that the applied doses of particles in the present in vitro study are much larger than anticipated exposures in vivo; this is the case for most of the other in vitro studies. Also, the history of particles before their interaction with target cells in vivo will be different depending on kinds of the targets; for example, (i) the particles in lung will interact with alveolar macrophages via pulmonary surfactants and (ii) the particles in a blood vessel will interact with blood cells via various serum proteins. Such biomolecules can modulate the outcome. In this sense, our findings mentioned above, albeit important, can not be directly translated to in vivo outcomes.

\section{Acknowledgements}

The authors thank for financial support by the Ministry of Education, Culture, Sports, Science and Technology (MEXT) in Japan (Grants-in-Aid for Scientific Research, Nos. 22686072, 23656489, and 25289276; Strategic Development of Research Infrastructure for Private Universities, Nos. S0901039 and S1201010), Iketani Science and Technology Foundation, Hosokawa Powder Technology Foundation, and the Information Center of Particle Technology, Japan. 
Fig. 1. LDH release (upper panels) and ATP content (lower panels) of three different cells as a function of NP surface area dose after 24-hours exposure to Silica-30 and -200 NPs (see Table 2): (a) Jurkat, (b) B16F10, and (c) J774.1. The dashed lines in upper and lower panels represent the percentages of LDH release and ATP content in the NP-free medium, respectively. The collected data of these assays were expressed as the mean \pm standard error of mean.

Fig. 2. Differential interference contrast images (upper panels) and fluorescence images of the optical section (lower panels) of four different cells after exposure to Silica-70 NPs: (a) Jurkat at $C_{\mathrm{NP}}=200$ $\mu \mathrm{g} / \mathrm{mL}$ after $t_{\exp }=2.0 \mathrm{~h}$; (b) B16F10 at $C_{\mathrm{NP}}=200 \mu \mathrm{g} / \mathrm{mL}$ after $t_{\exp }=1.0 \mathrm{~h}$; (c) $\mathrm{J} 774.1$ at $C_{\mathrm{NP}}=200$ $\mu \mathrm{g} / \mathrm{mL}$ after $t_{\exp }=1.0 \mathrm{~h}$; (d) RBC at $C_{\mathrm{NP}}=100 \mu \mathrm{g} / \mathrm{mL}$ after $t_{\exp }=0.5 \mathrm{~h}$. The scale bars in panels a-d are 10, 20, 10, and $2 \mu \mathrm{m}$, respectively.

Fig. 3. LDH release (upper panels) and ATP content (lower panels) of three different cells as a function of NP surface area dose after 2-hours exposure to Silica-30, -70, -200, and -500 NPs (see Table 2): (a) Jurkat, (b) B16F10, and (c) J774.1. The dashed lines in upper and lower panels represent the percentages of LDH release and ATP content in the NP-free medium, respectively. The collected data of these assays were expressed as the mean \pm standard error of mean.

Fig. 4. (a) Hemolysis of RBCs as a function of NP mass dose, $C_{\mathrm{NP}}$, after 4-hours exposure to Silica-50, -70, -200, and -500 NPs (see Table 2). The solid lines are the guides for the eyes. (b) Same as panel a, but plotted as a function of NP surface area dose, where the dashed line represents the hemolysis in the NP-free medium. The collected data of hemolysis assay were expressed as the mean \pm standard error of mean.

Fig. 5. (a,b) Illustration of AFM measurements of interaction forces between the microsphere and soft sample: (a) a living cell and (b) a GUV. (c,d) A representative of the force-displacement curves during compression (upper, red colored) and decompression (lower, blue colored) measured between a 10- $\mu \mathrm{m}$ silica microsphere and a soft sample at the Z-scan speed of 1.0-1.3 $\mu \mathrm{m} / \mathrm{s}$ with no dwell time: (c) a 
B16F10 cell in a serum-free culture medium of DMEM and (d) a 40- $\mu$ m GUV composed of DOPCs in DPBS containing vesicles, where the inset represents the magnification of the forces ranging from -0.2 to $1.2 \mathrm{nN}$. 
Table 1

The properties of vesicles and mammalian cells employed in the present study.

\begin{tabular}{lccccc}
\hline Cell & $\begin{array}{c}\text { Membrane } \\
\text { proteins }\end{array}$ & Nucleated & Adherent & Endocytosis & Phagocytosis \\
\hline DOPC vesicles & No & No & No & No & No \\
Erythrocyte (RBC) & Yes & No & No & No & No \\
Jurkat & Yes & Yes & No & Yes & No \\
B16F10 & Yes & Yes & Yes & Yes & No \\
J774.1 & Yes & Yes & Yes & Yes & Yes \\
\hline
\end{tabular}


Table 2

The results of characterization of the silica NPs, the SUVs, and the cells at $25.0{ }^{\circ} \mathrm{C}$.

\begin{tabular}{|c|c|c|c|c|}
\hline Dispersoid & Medium & $\begin{array}{l}\text { Z-average diameter } \\
\qquad(\mathrm{nm})^{a}\end{array}$ & $\mathrm{PDI}^{b}$ & $\begin{array}{c}\text { Zeta potential } \\
\qquad(\mathrm{mV})^{a}\end{array}$ \\
\hline \multirow[t]{2}{*}{ Silica-30 } & 1-mM NaCl & $28 \pm 1$ & 0.09 & $-35 \pm 1$ \\
\hline & DPBS & $30 \pm 1$ & 0.21 & $-20 \pm 1$ \\
\hline \multirow[t]{2}{*}{ Silica-50 } & 1-mM NaCl & $50 \pm 1$ & 0.04 & $-37 \pm 2$ \\
\hline & DPBS & $50 \pm 1$ & 0.07 & $-19 \pm 1$ \\
\hline \multirow[t]{2}{*}{ Silica-70 } & 1-mM NaCl & $55 \pm 1$ & 0.04 & $-39 \pm 2$ \\
\hline & DPBS & $55 \pm 1$ & 0.06 & $-19 \pm 1$ \\
\hline \multirow[t]{2}{*}{ Silica-200 } & 1-mM NaCl & $156 \pm 1$ & 0.01 & $-57 \pm 1$ \\
\hline & DPBS & $152 \pm 1$ & 0.02 & $-27 \pm 2$ \\
\hline \multirow[t]{2}{*}{ Silica-500 } & 1-mM NaCl & $461 \pm 5$ & 0.02 & $-73 \pm 1$ \\
\hline & DPBS & $476 \pm 7$ & 0.03 & $-26 \pm 2$ \\
\hline \multirow[t]{2}{*}{ DOPC SUVs } & water & $161 \pm 5$ & 0.39 & $-25 \pm 1$ \\
\hline & DPBS & $232 \pm 4$ & 0.41 & $-7 \pm 1$ \\
\hline Rabbit RBCs & $100-\mathrm{mM} \mathrm{NaCl}$ & $6 \pm 1 \mu \mathrm{m}^{c}$ & & $-9 \pm 1$ \\
\hline Jurkat cells & $100-\mathrm{mM} \mathrm{NaCl}$ & $11 \pm 5 \mu \mathrm{m}^{c}$ & & $-11 \pm 1$ \\
\hline B16F10 cells & $100-\mathrm{mM} \mathrm{NaCl}$ & $13 \pm 5 \mu \mathrm{m}^{c}$ & & $-14 \pm 2$ \\
\hline J774.1 cells & $100-\mathrm{mM} \mathrm{NaCl}$ & $14 \pm 2 \mu \mathrm{m}^{c}$ & & $-16 \pm 1$ \\
\hline
\end{tabular}

${ }^{a}$ The collected data were expressed as the mean \pm standard deviation (s.d.).

${ }^{b}$ Polydispersity index.

$c$ Average diameter of suspended cells estimated by a TC10 automated cell counter (Bio-Rad Laboratories, USA). 


\section{References}

[1] R.K. Iler, The surface chemistry of silica, in: The Chemistry of Silica, Wiley-Interscience, New York, 1979, pp. 622-729.

[2] R.K. Iler, Silica in biology, in: The Chemistry of Silica, Wiley-Interscience, New York, 1979, pp. 730-801.

[3] V. Castranova, V. Vallyathan, W.E. Wallace (Eds.), Silica and Silica-Induced Lung Diseases, CRC Press, Boca Raton, 1995.

[4] B. Fubini, Health effects of silica, in: A.P. Legrand (Ed.) The Surface Properties of Silicas, John Wiley \& Sons, Chichester, 1998, pp. 415-464.

[5] I.I. Slowing, C.-W. Wu, J.L. Vivero-Escoto, V.S.-Y. Lin, Mesoporous silica nanoparticles for reducing hemolytic activity towards mammalian red blood cells, Small 5 (2009) 57-62.

[6] Y.-S. Lin, C.L. Haynes, Synthesis and characterization of biocompatible and size-tunable multifunctional porous silica nanoparticles, Chem. Mater. 21 (2009) 3979-3986.

[7] Y.-S. Lin, C.L. Haynes, Impacts of mesoporous silica nanoparticle size, pore ordering, and pore integrity on hemolytic activity, J. Am. Chem. Soc. 132 (2010) 4834-4842.

[8] Y. Zhao, X. Sun, G. Zhang, B.G. Trewyn, I.I. Slowing, V.S.-Y. Lin, Interaction of mesoporous silica nanoparticles with human red blood cell membranes: Size and surface effects, ACS Nano 5 (2011) 1366-1375.

[9] T. Yu, A. Malugin, H. Ghandehari, Impact of silica nanoparticle design on cellular toxicity and hemolytic activity, ACS Nano 5 (2011) 5717-5728.

[10] A. Petushkov, N. Ndiege, A.K. Salem, S.C. Larsen, Toxicity of silica nanomaterials: Zeolites, mesoporous silica, and amorphous silica nanoparticles, in: C.F. James (Ed.) Advances in Molecular Toxicology, Elsevier, 2010, pp. 223-266.

[11] W. Wallace, M.J. Keane, D.K. Murray, W.P. Chisholm, A.D. Maynard, T.-m. Ong, Phospholipid lung surfactant and nanoparticle surface toxicity: Lessons from diesel soots and silicate dusts, J. Nanoparticle Res. 9 (2007) 23-38. 
[12] M.A. Dobrovolskaia, S.E. McNeil (Eds.), Handbook of Immunological Properties of Engineered Nanomaterials, World Scientific, Singapore, 2013.

[13] J.D. Harley, J. Margolis, Haemolytic activity of colloidal silica, Nature 189 (1961) 1010-1011.

[14] K. Stalder, W. Stöber, Haemolytic activity of suspensions of different silica modifications and inert dusts, Nature 207 (1965) 874-875.

[15] V. Murashov, M. Harper, E. Demchuk, Impact of silanol surface density on the toxicity of silica aerosols measured by erythrocyte haemolysis, J. Occupat. Environ. Hygiene 3 (2006) 718 - 723.

[16] K. Stalder, Untersuchungen zum Mechanismus der Zytotoxizität silikogener Stäube, Beitr. Silikose-Forschung (Pneumokoniose) 5 (1970) 237-314.

[17] S.V. Singh, P.N. Viswanathan, Q. Rahman, Interaction between erythrocyte plasma membrane and silicate dusts, Environ. Health Perspect. 51 (1983) 55-60.

[18] J. Summerton, S. Hoenig, C. Butler II, M. Chvapil, The mechanism of hemolysis by silica and its bearing on silicosis, Exp. Mol. Pathol. 26 (1977) 113-128.

[19] F. Kozin, B. Millstein, G. Mandel, N. Mandel, Silica-induced membranolysis: A study of different structural forms of crystalline and amorphous silica and the effects of protein adsorption, J. Colloid Interface Sci. 88 (1982) 326-337.

[20] H.-W. Schlipköter, A. Brockhaus, Die Hemmung der experimentellen Silikose durch subcutane Verabreichung von Polyvinylpyridin-N-Oxyd, Klinische Wochenschrift 39 (1961) 1182-1189.

[21] T. Nash, A.C. Allison, J.S. Harington, Physico-chemical properties of silica in relation to its toxicity, Nature 210 (1966) 259-261.

[22] R.P. Nolan, A.M. Langer, J.S. Harington, G. Oster, I.J. Selikoff, Quartz hemolysis as related to its surface functionalities, Environ. Res. 26 (1981) 503-520.

[23] B. Wildt, R.A. Malinauskas, R.P. Brown, The effects of engineered nanomaterials on erythrocytes, in: M.A. Dobrovolskaia, S.E. McNeil (Eds.) Handbook of Immunological Properties of Engineered Nanomaterials, World Scientific, Singapore, 2013. 
[24] Z. Tao, B.B. Toms, J. Goodisman, T. Asefa, Mesoporosity and functional group dependent endocytosis and cytotoxicity of silica nanomaterials, Chem. Res. Toxicol. 22 (2009) 1869-1880.

[25] H.W. Kim, E.-K. Ahn, B.K. Jee, H.-K. Yoon, K.H. Lee, Y. Lim, Nanoparticulate-induced toxicity and related mechanism in vitro and in vivo, J. Nanoparticle Res. 11 (2009) 55-65.

[26] K.M. Waters, L.M. Masiello, R.C. Zangar, B.J. Tarasevich, N.J. Karin, R.D. Quesenberry, S. Bandyopadhyay, J.G. Teeguarden, J.G. Pounds, B.D. Thrall, Macrophage responses to silica nanoparticles are highly conserved across particle sizes, Toxicol. Sci. 107 (2009) 553-569.

[27] L.C.J. Thomassen, A. Aerts, V. Rabolli, D. Lison, L. Gonzalez, M. Kirsch-Volders, D. Napierska, P.H. Hoet, C.E.A. Kirschhock, J.A. Martens, Synthesis and characterization of stable monodisperse silica nanoparticle sols for in vitro cytotoxicity testing, Langmuir 26 (2009) 328-335.

[28] J. Geys, B. Nemery, P.H.M. Hoet, Assay conditions can influence the outcome of cytotoxicity tests of nanomaterials: Better assay characterization is needed to compare studies, Toxicol. in Vitro 24 (2010) 620-629.

[29] H. Yang, Q. Wu, M. Tang, X. Liu, H. Deng, L. Kong, Z. Lu, In vitro study of silica nanoparticleinduced cytotoxicity based on real-time cell electronic sensing system, J. Nanosci. Nanotechnol. 10 (2010) 561-568.

[30] M. Ghiazza, M. Polimeni, I. Fenoglio, E. Gazzano, D. Ghigo, B. Fubini, Does vitreous silica contradict the toxicity of the crystalline silica paradigm?, Chem. Res. Toxicol. 23 (2010) 620-629.

[31] E.-J. Park, K. Park, Oxidative stress and pro-inflammatory responses induced by silica nanoparticles in vivo and in vitro, Toxicol. Lett. 184 (2009) 18-25.

[32] W. Lin, Y.-W. Huang, X.-D. Zhou, Y. Ma, In vitro toxicity of silica nanoparticles in human lung cancer cells, Toxicol. Appl. Pharmacol. 217 (2006) 252-259.

[33] M. Horie, K. Nishio, K. Fujita, S. Endoh, A. Miyauchi, Y. Saito, H. Iwahashi, K. Yamamoto, H. Murayama, H. Nakano, N. Nanashima, E. Niki, Y. Yoshida, Protein adsorption of ultrafine metal oxide and its influence on cytotoxicity toward cultured cells, Chem. Res. Toxicol. 22 (2009) 543553. 
[34] J.-S. Chang, K.L.B. Chang, D.-F. Hwang, Z.-L. Kong, In vitro cytotoxicitiy of silica nanoparticles at high concentrations strongly depends on the metabolic activity type of the cell Line, Environ. Sci. Technol. 41 (2007) 2064-2068.

[35] H.-J. Eom, J. Choi, Oxidative stress of silica nanoparticles in human bronchial epithelial cell, Beas2B, Toxicol. in Vitro 23 (2009) 1326-1332.

[36] M. Chen, A. von Mikecz, Formation of nucleoplasmic protein aggregates impairs nuclear function in response to $\mathrm{SiO}_{2}$ nanoparticles, Exp. Cell Res. 305 (2005) 51-62.

[37] C. Fede, F. Selvestrel, C. Compagnin, M. Mognato, F. Mancin, E. Reddi, L. Celotti, The toxicity outcome of silica nanoparticles (Ludox $\left.{ }^{\circledR}\right)$ is influenced by testing techniques and treatment modalities, Anal. Bioanal. Chem. 404 (2012) 1789-1802.

[38] D. Napierska, L.C.J. Thomassen, V. Rabolli, D. Lison, L. Gonzalez, M. Kirsch-Volders, J.A. Martens, P.H. Hoet, Size-dependent cytotoxicity of nonodisperse silica nanoparticles in human endothelial cells, Small 5 (2009) 846-853.

[39] A.T. Bauer, E.A. Strozyk, C. Gorzelanny, C. Westerhausen, A. Desch, M.F. Schneider, S.W. Schneider, Cytotoxicity of silica nanoparticles through exocytosis of von Willebrand factor and necrotic cell death in primary human endothelial cells, Biomaterials 32 (2011) 8385-8393.

[40] J.J. Corbalan, C. Medina, A. Jacoby, T. Malinski, M.W. Radomski, Amorphous silica nanoparticles trigger nitric oxide/peroxynitrite imbalance in human endothelial cells: Inflammatory and cytotoxic effects, Int. J. Nanomed. 6 (2011) 2821-2835.

[41] S.C. Brown, M. Kamal, N. Nasreen, A. Baumuratov, P. Sharma, V.B. Antony, B.M. Moudgil, Influence of shape, adhension and simulated lung mechanics on amorphous silica nanoparticle toxicity, Adv. Powder Technol. 18 (2007) 69-79.

[42] K.O. Yu, C.M. Grabinski, A.M. Schrand, R.C. Murdock, W. Wang, B. Gu, J.J. Schlager, S.M. Hussain, Toxicity of amorphous silica nanoparticles in mouse keratinocytes, J. Nanoparticle Res. 11 (2009) 15-24. 
[43] Y. Ye, J. Liu, J. Xu, L. Sun, M. Chen, M. Lan, Nano-SiO 2 induces apoptosis via activation of p53 and Bax mediated by oxidative stress in human hepatic cell line, Toxicol. in Vitro 24 (2010) 751758.

[44] Y. Ye, J. Liu, M. Chen, L. Sun, M. Lan, In vitro toxicity of silica nanoparticles in myocardial cells, Environ. Toxicol. Pharmacol. 29 (2010) 131-137.

[45] F. Wang, F. Gao, M. Lan, H. Yuan, Y. Huang, J. Liu, Oxidative stress contributes to silica nanoparticle-induced cytotoxicity in human embryonic kidney cells, Toxicol. in Vitro 23 (2009) 808-815.

[46] A.J. Jabbour, R. Iyer, R.K. Scheule, A. Holian, Potential intracellular messengers involved in silica stimulation of alveolar macrophages, in: V. Castranova, V. Vallyathan, W.E. Wallace (Eds.) Silica and Silica-Induced Lung Diseases, CRC Press, Boca Raton, 1995, pp. 137-149.

[47] H. Shinto, Y. Ohta, T. Fukasawa, Adhesion of melanoma cells to the microsphere surface is reduced by exposure to nanoparticles, Adv. Powder Technol. 23 (2012) 693-699.

[48] A. Moscho, O. Orwar, D.T. Chiu, B.P. Modi, R.N. Zare, Rapid preparation of giant unilamellar vesicles, Proc. Nat. Acad. Sci. 93 (1996) 11443-11447.

[49] H. Shinto, Y. Aso, T. Fukasawa, K. Higashitani, Adhesion of melanoma cells to the surfaces of microspheres studied by atomic force microscopy, Colloids Surf. B: Biointerfaces 91 (2012) 114121.

[50] H. Shinto, T. Hirata, T. Fukasawa, S. Fujii, H. Maeda, M. Okada, Y. Nakamura, T. Furuzono, Effect of interfacial serum proteins on melanoma cell adhesion to biodegradable poly(L-lactic acid) microspheres coated with hydroxyapatite, Colloids Surf. B: Biointerfaces 108 (2013) 8-15.

[51] C. Zhang, Y. Xu, J. Gu, S.F. Schlossman, A cell surface receptor defined by a mAb mediates a unique type of cell death similar to oncosis, Proc. Nat. Acad. Sci. 95 (1998) 6290-6295.

[52] J. Lam, M. Herant, M. Dembo, V. Heinrich, Baseline mechanical characterization of J774 macrophages, Biophys. J. 96 (2009) 248-254. 
[53] M. Diociaiuti, F. Bordi, L. Gataleta, G. Baldo, P. Crateri, L. Paoletti, Morphological and functional alterations of human erythrocytes induced by $\mathrm{SiO}_{2}$ particles: An electron microscopy and dielectric spectroscopy study, Environ. Res. 80 (1999) 197-207.

[54] S. Iyer, R.M. Gaikwad, V. Subba-Rao, C.D. Woodworth, I. Sokolov, Atomic force microscopy detects differences in the surface brush of normal and cancerous cells, Nat. Nanotechnol. 4 (2009) 389-393.

[55] A.E. Nel, L. Mädler, D. Velegol, T. Xia, E.M.V. Hoek, P. Somasundaran, F. Klaessig, V. Castranova, M. Thompson, Understanding biophysicochemical interactions at the nano-bio interface, Nat. Mater. 8 (2009) 543-557.

[56] G. Weissman, G.A. Rita, Molecular basis of gouty inflammation: Interaction of monosodium urate crystals with lysosomes and liposomes, Nat. New Biol. 240 (1972) 167-172.

[57] K. Esumi, T. Yamada, Characterization of a phospholipid adsorbed layer on silica from small unilamellar vesicles, Langmuir 9 (1993) 622-624.

[58] T.A. Oleson, N. Sahai, J.A. Pedersen, Electrostatic effects on deposition of multiple phospholipid bilayers at oxide surfaces, J. Colloid Interface Sci. 352 (2010) 327-336.

[59] R. Rapuano, A.M. Carmona-Ribeiro, Physical adsorption of bilayer membranes on silica, J. Colloid Interface Sci. 193 (1997) 104-111.

[60] S.P. Moura, A.M. Carmona-Ribeiro, Biomimetic particles: Optimization of phospholipid bilayer coverage on silica and colloid stabilization, Langmuir 21 (2005) 10160-10164.

[61] T.A. Oleson, N. Sahai, Oxide-dependent adsorption of a model membrane phospholipid, dipalmitoylphosphatidylcholine: Bulk adsorption isotherms, Langmuir 24 (2008) 4865-4873.

[62] J. Xu, M.J. Stevens, T.A. Oleson, J.A. Last, N. Sahai, Role of oxide surface chemistry and phospholipid phase on adsorption and self-assembly: Isotherms and atomic force microscopy, J. Phys. Chem. C 113 (2009) 2187-2196.

[63] Y. Chunbo, Z. Daqing, L. Aizhuo, N. Jiazuan, A NMR study of the interaction of silica with dipalmitoylphosphatidylcholine liposomes, J. Colloid Interface Sci. 172 (1995) 536-538. 
[64] S. Mornet, O. Lambert, E. Duguet, A. Brisson, The formation of supported lipid bilayers on silica nanoparticles revealed by cryoelectron microscopy, Nano Lett. 5 (2004) 281-285.

[65] B. Wang, L. Zhang, S.C. Bae, S. Granick, Nanoparticle-induced surface reconstruction of phospholipid membranes, Proc. Nat. Acad. Sci. 105 (2008) 18171-18175.

[66] S. Savarala, F. Monson, M.A. Ilies, S.L. Wunder, Supported lipid bilayer nanosystems: Stabilization by undulatory-protrusion forces and destabilization by lipid bridging, Langmuir 27 (2011) 5850-5861.

[67] H. Wang, J. Drazenovic, Z. Luo, J. Zhang, H. Zhou, S.L. Wunder, Mechanism of supported bilayer formation of zwitterionic lipids on $\mathrm{SiO}_{2}$ nanoparticles and structure of the stable colloids, RSC Adv. 2 (2012) 11336-11348.

[68] A. Vakurov, R. Brydson, A. Nelson, Electrochemical modeling of the silica nanoparticlebiomembrane interaction, Langmuir 28 (2011) 1246-1255.

[69] M.R.R. de Planque, S. Aghdaei, T. Roose, H. Morgan, Electrophysiological characterization of membrane disruption by nanoparticles, ACS Nano 5 (2011) 3599-3606.

[70] R.P. Richter, R. Bérat, A.R. Brisson, Formation of solid-supported lipid bilayers: An integrated view, Langmuir 22 (2006) 3497-3505.

[71] E. Reimhult, F. Höök, B. Kasemo, Vesicle adsorption on $\mathrm{SiO}_{2}$ and $\mathrm{TiO}_{2}$ : Dependence on vesicle size, J. Chem. Phys. 117 (2002) 7401-7404.

[72] B. Seantier, C. Breffa, O. Félix, G. Decher, Dissipation-enhanced quartz crystal microbalance studies on the experimental parameters controlling the formation of supported lipid bilayers, J. Phys. Chem. B 109 (2005) 21755-21765.

[73] B. Seantier, B. Kasemo, Influence of mono- and divalent ions on the formation of supported phospholipid bilayers via vesicle adsorption, Langmuir 25 (2009) 5767-5772.

[74] R.P. Richter, A. Brisson, Characterization of lipid bilayers and protein assemblies supported on rough surfaces by atomic force microscopy, Langmuir 19 (2003) 1632-1640. 


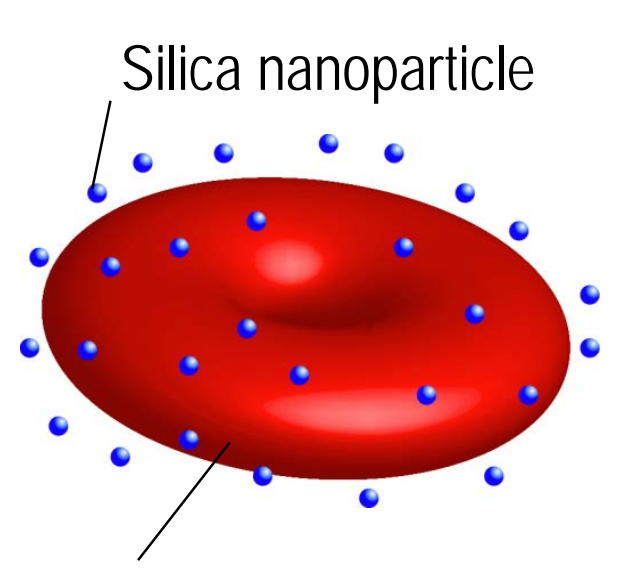

Red blood cell

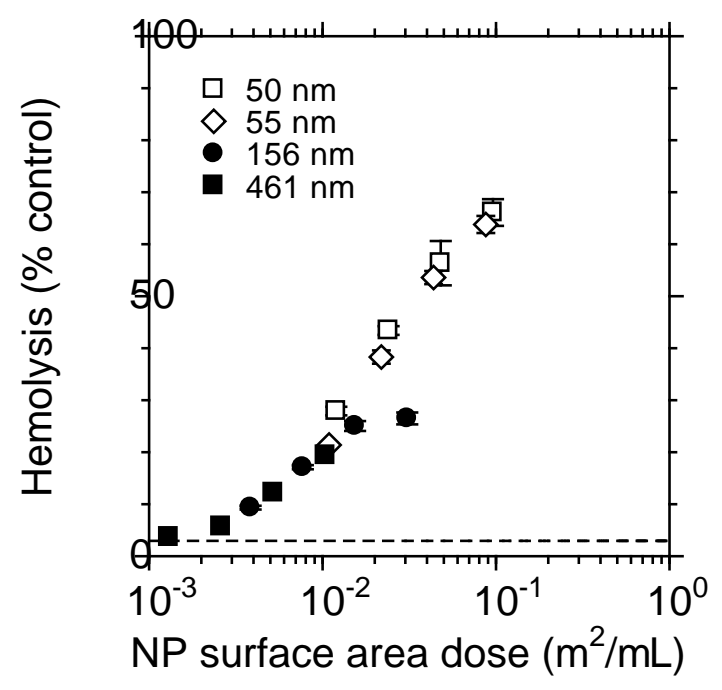

Graphical Abstract: Shinto et al. 
(a) Jurkat

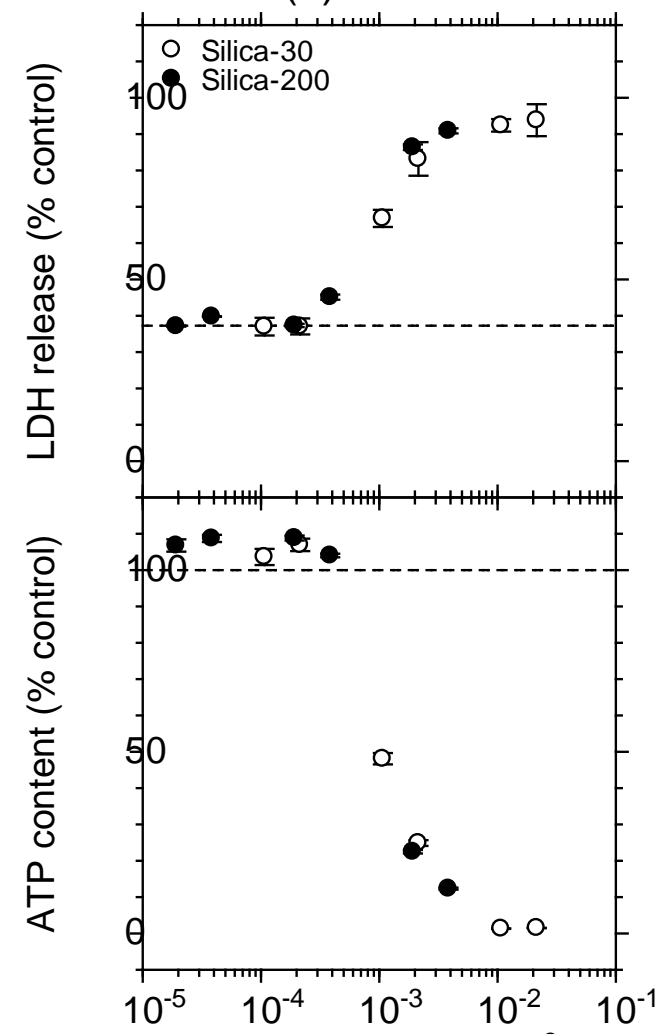

NP surface area dose $\left(\mathrm{m}^{2} / \mathrm{mL}\right)$ (b) B16F10

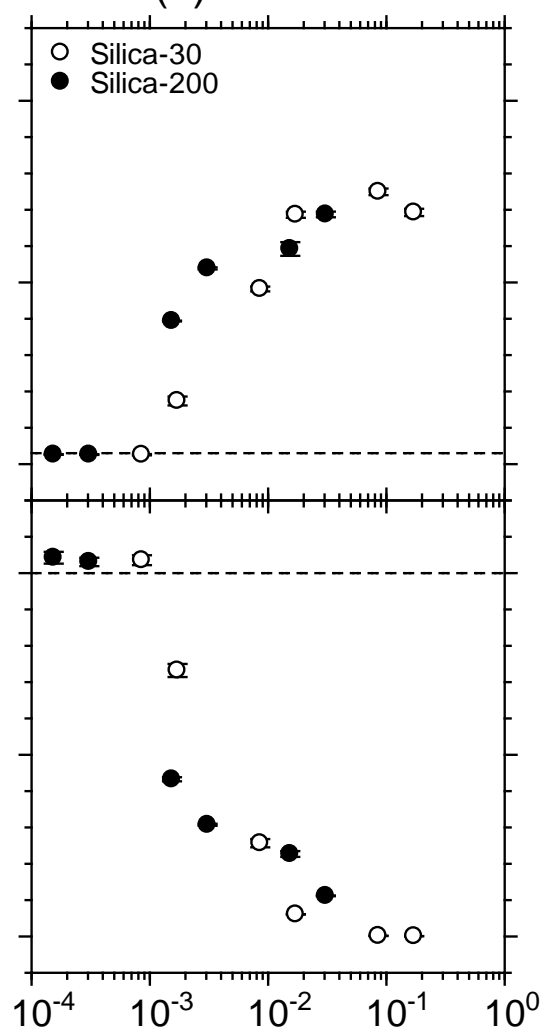

NP surface area dose $\left(\mathrm{m}^{2} / \mathrm{mL}\right)$ (c) 3774.1

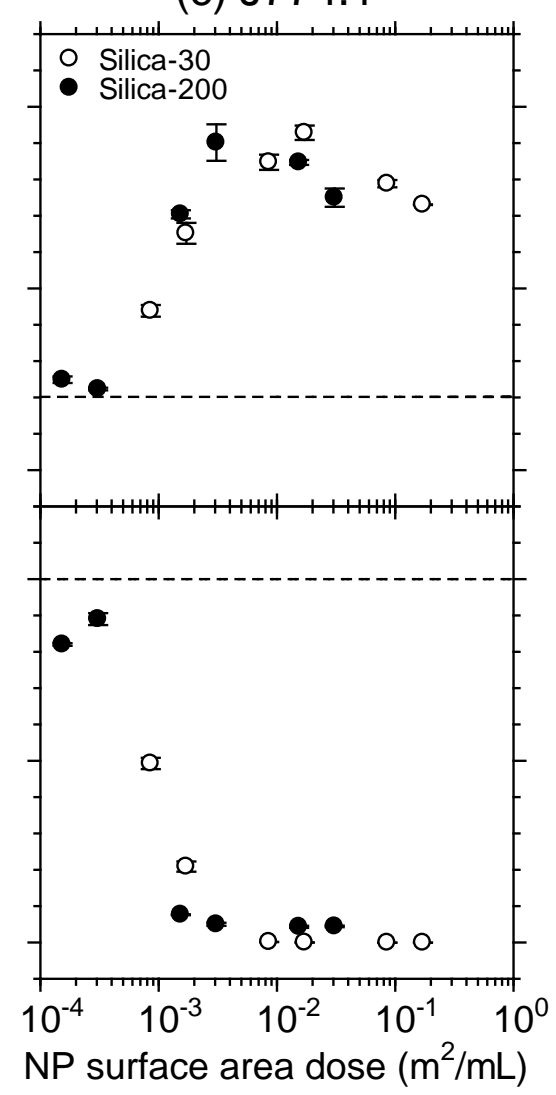

Figure 1 Shinto et al. 

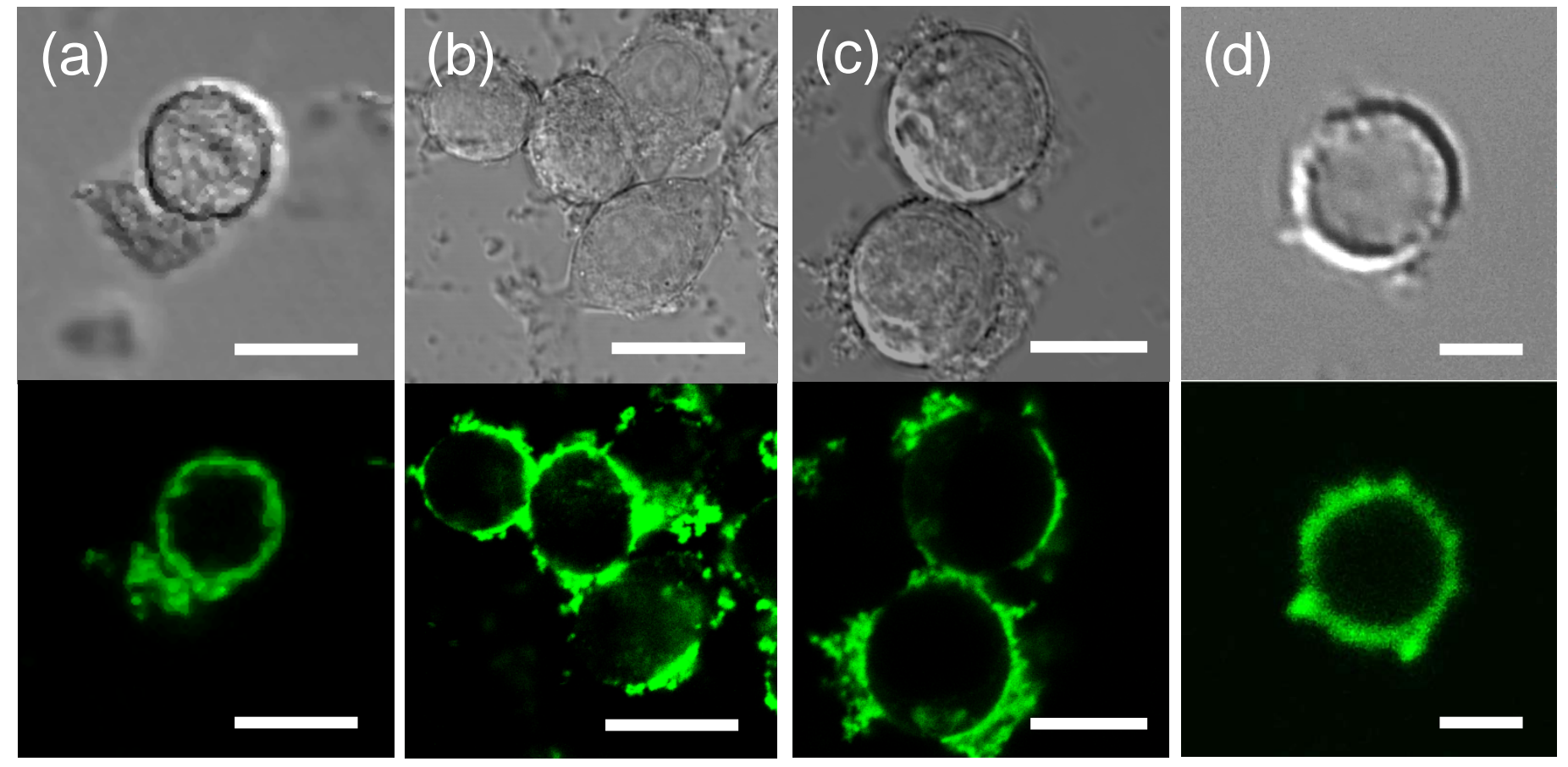

Figure 2 Shinto et al. 
(a) Jurkat

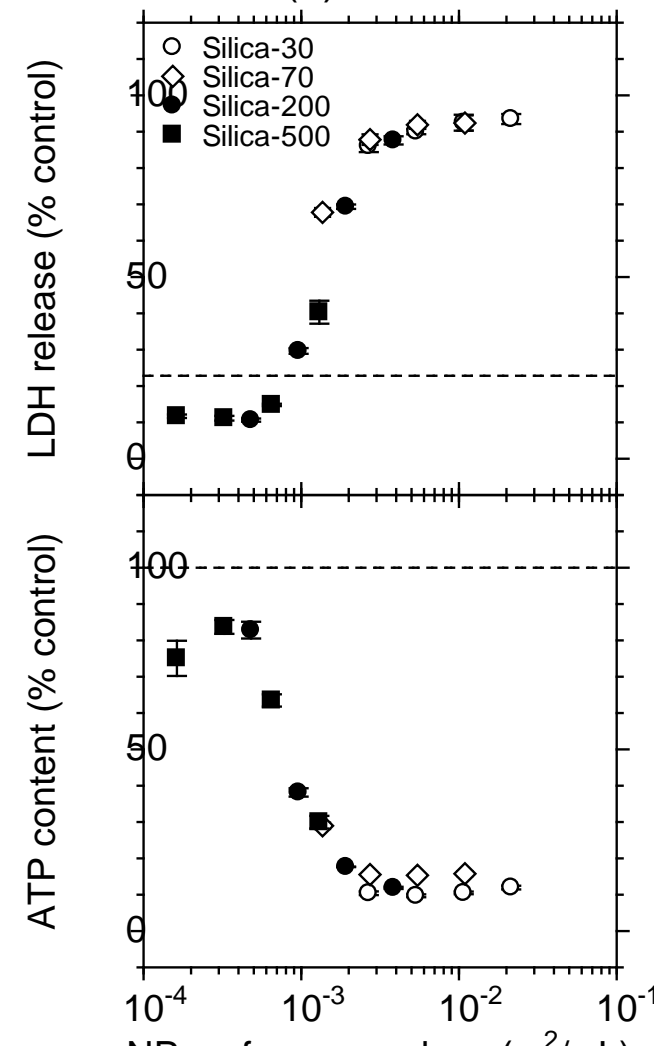

(b) B16F10

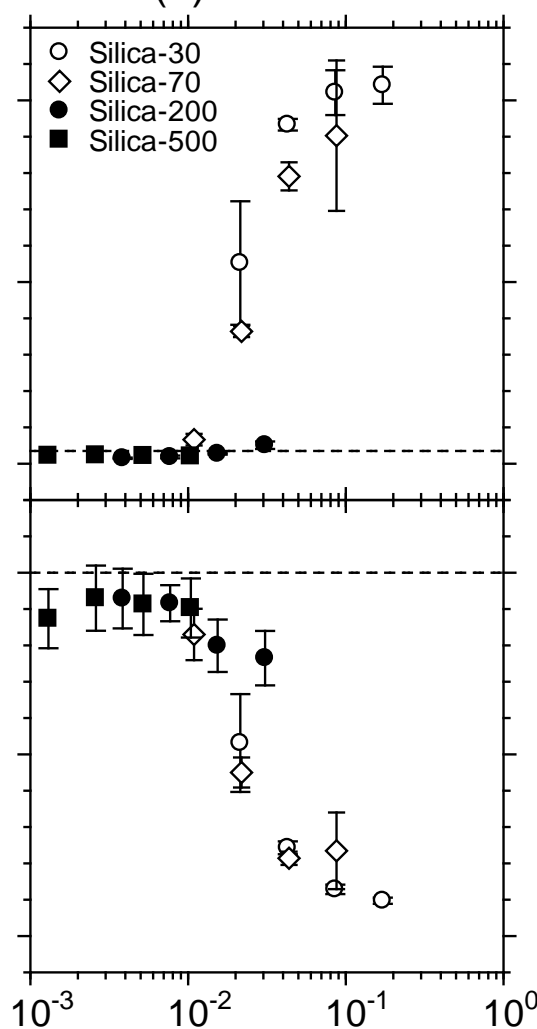

(c) 3774.1

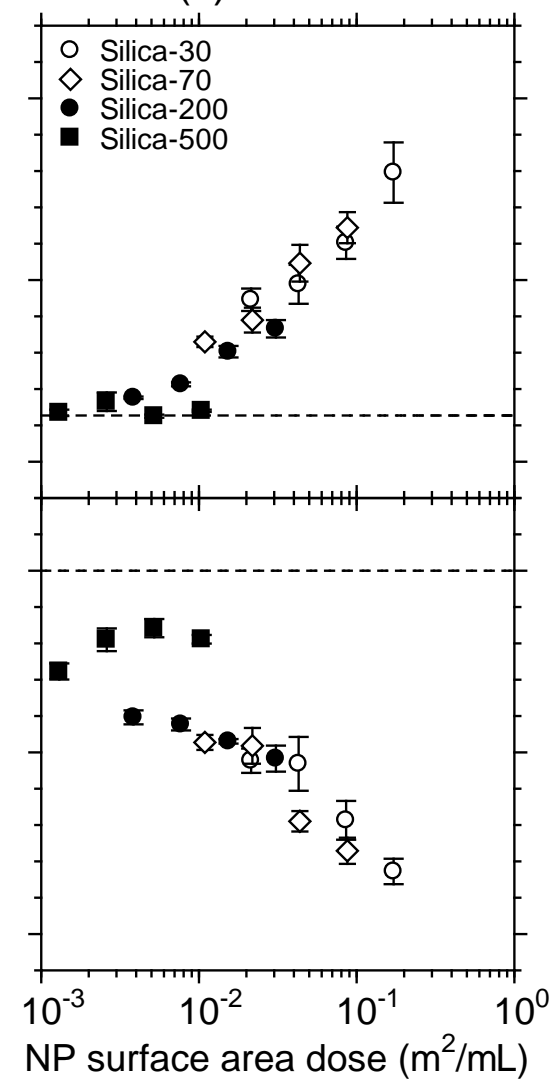

Figure 3 Shinto et al. 


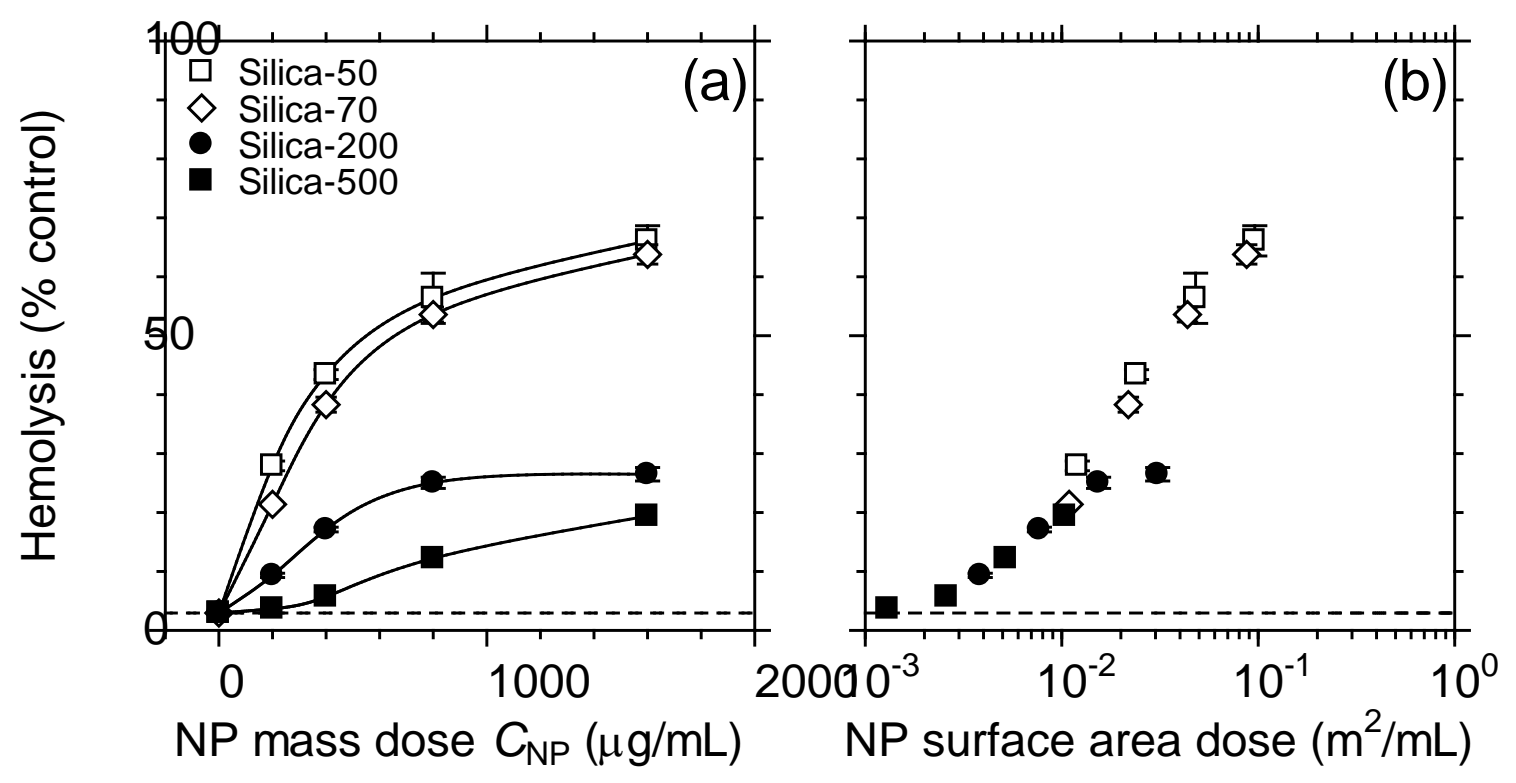

Figure 4 Shinto et al. 
(a) $\mathrm{Y}$
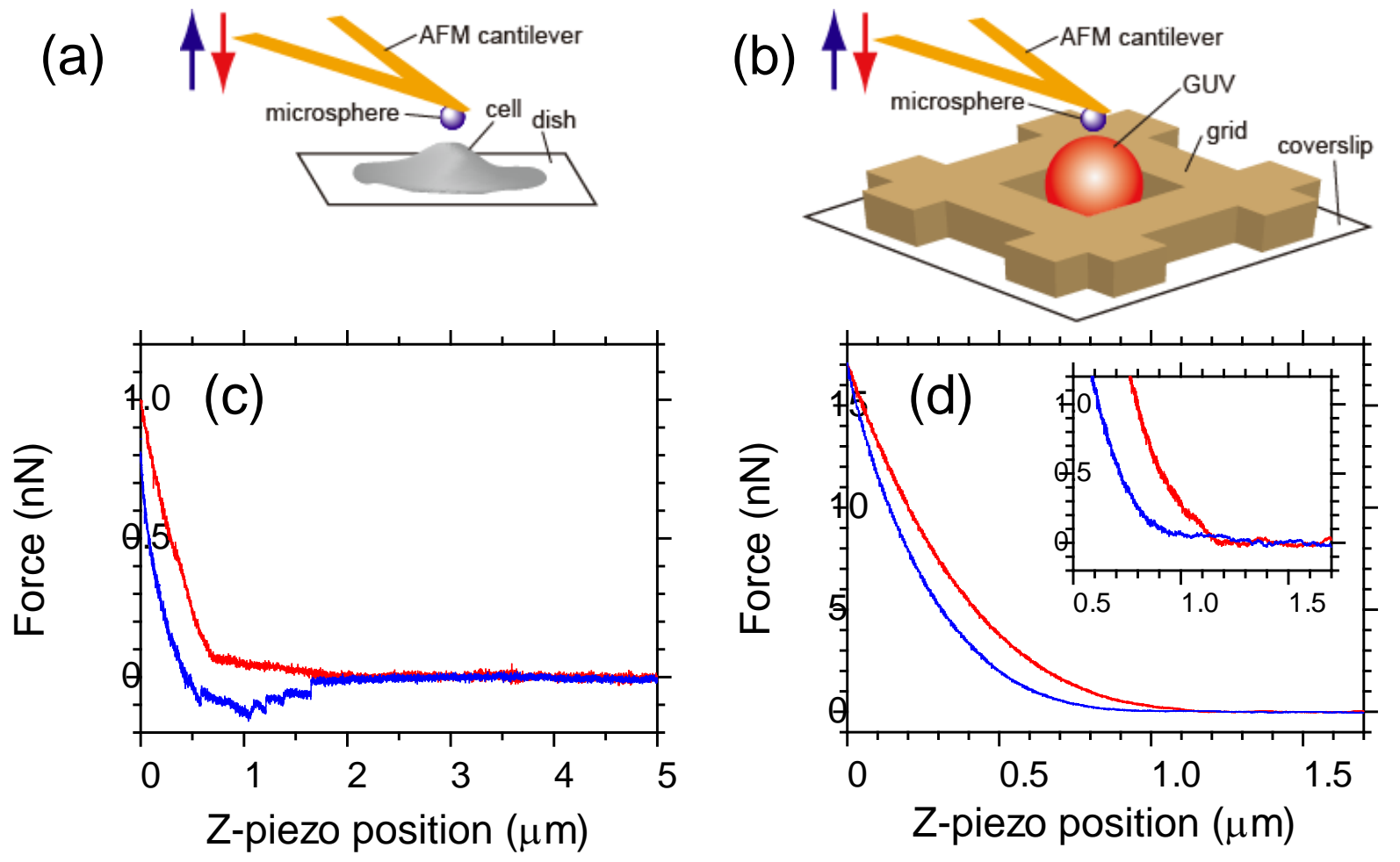

Figure 5 Shinto et al. 
(a) Jurkat

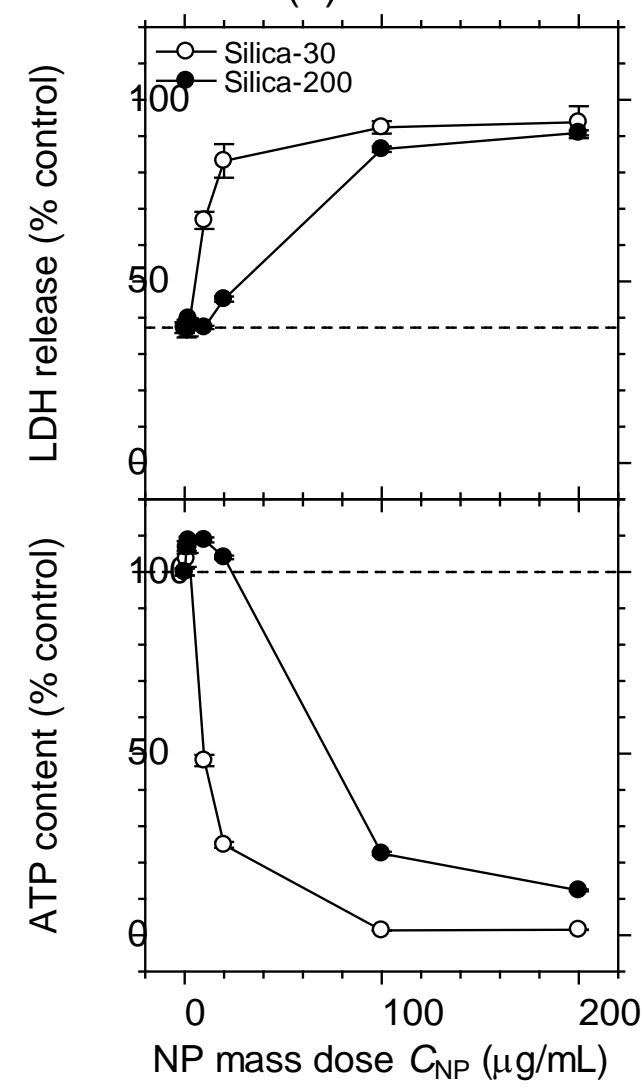

(b) B16F10

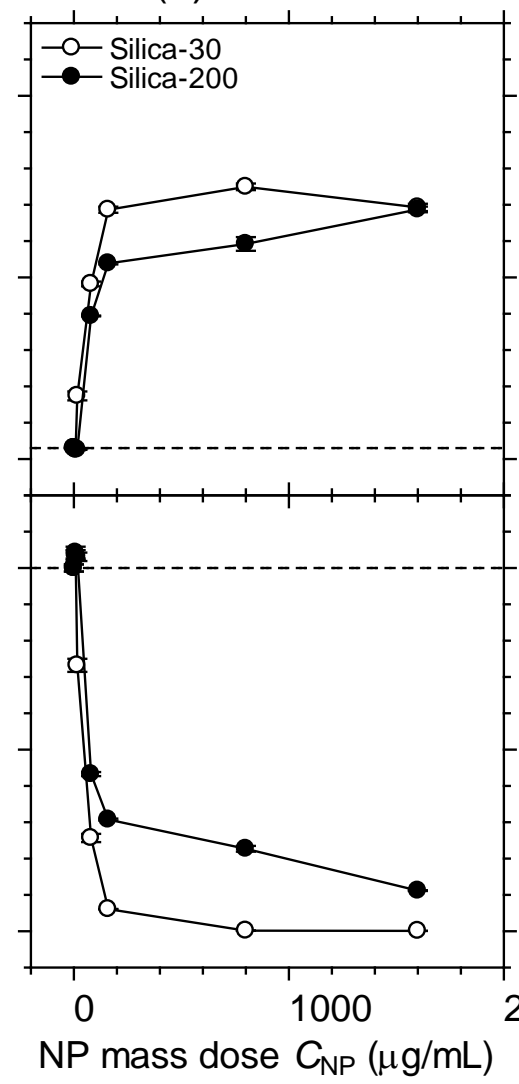

(c) 3774.1

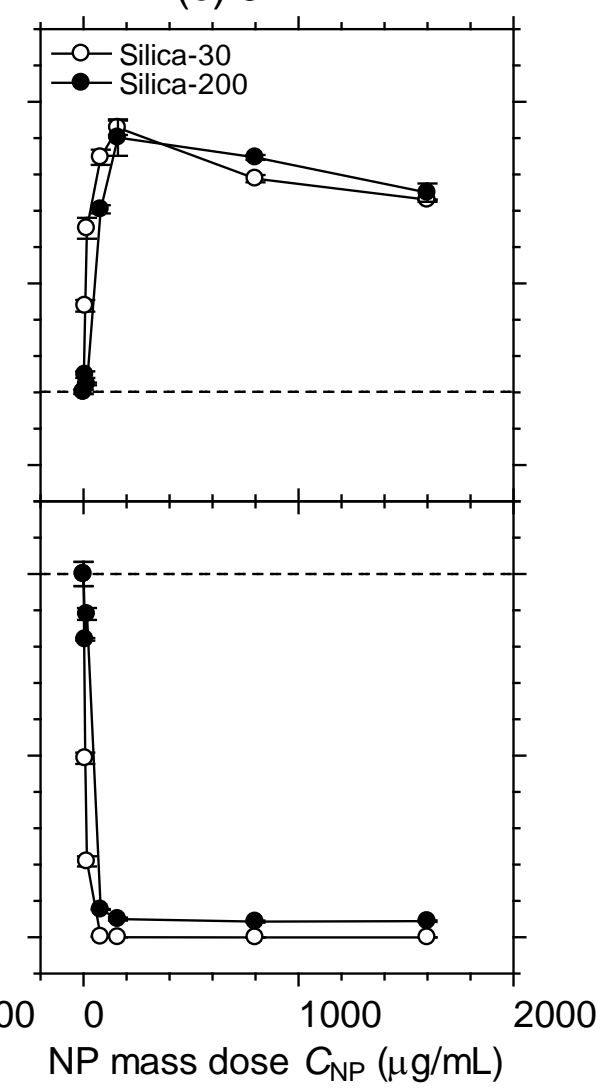

Figure S1 Shinto et al. 
(a) Jurkat

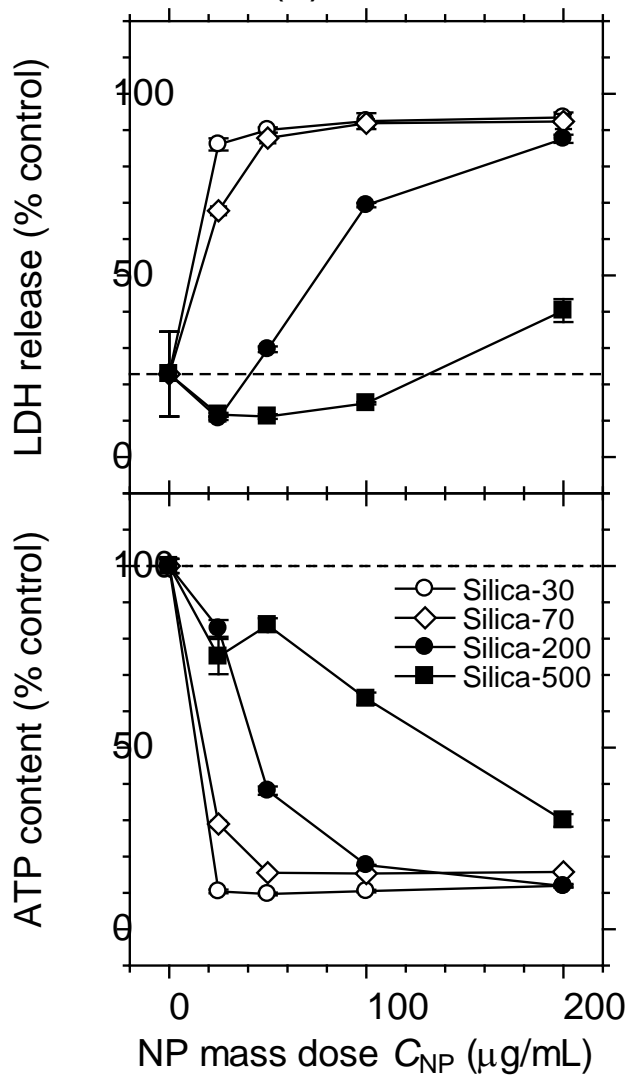

(b) B16F10

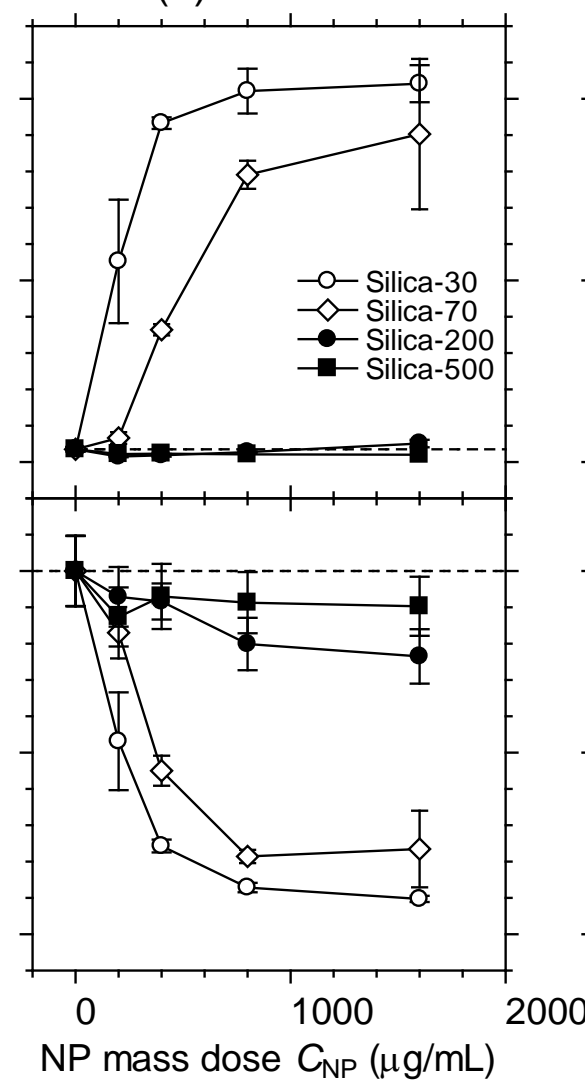

(c) $\mathrm{J} 774.1$

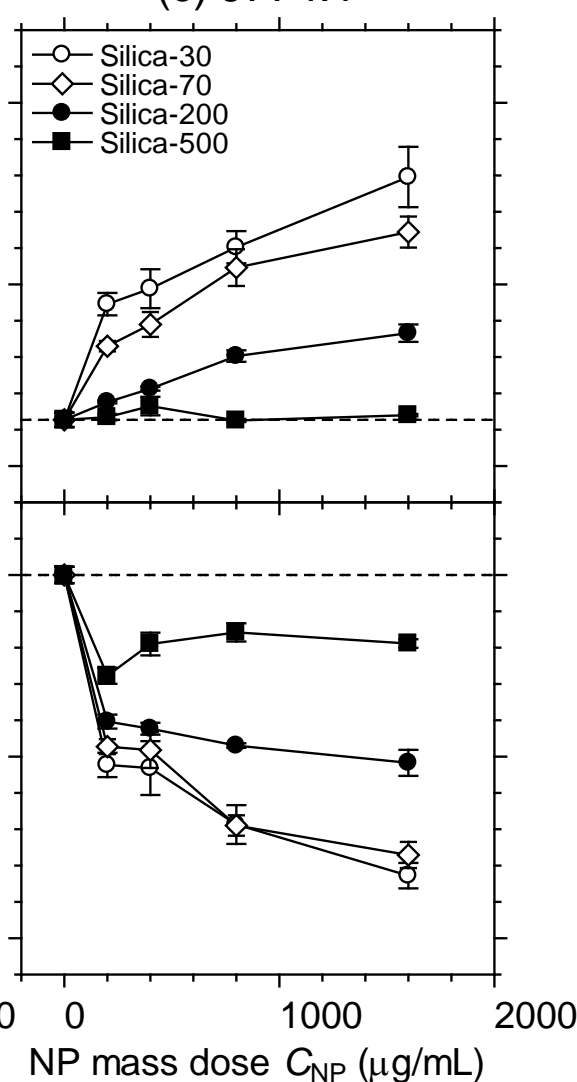




\section{Cell membrane disruption induced by amorphous silica nanoparticles in erythrocytes, lymphocytes, malignant melanocytes, and macrophages}

Hiroyuki Shinto, ${ }^{\dagger, *}$ Tomonori Fukasawa, Kosuke Yoshisue, Mikihito Tezuka, and Mayumi Orita

Department of Chemical Engineering, Kyoto University, Katsura, Nishikyo-ku, Kyoto 615-8510, Japan

${ }^{\dagger}$ Present address: Department of Chemical Engineering, Fukuoka University, 8-19-1 Nanakuma, Jonan-ku, Fukuoka 814-0180, Japan

${ }^{*}$ Author to whom correspondence should be addressed. Phone: +81-92-871-6631, Fax: +81-92-8656031, e-mail: hshinto@fukuoka-u.ac.jp 
(a) Jurkat

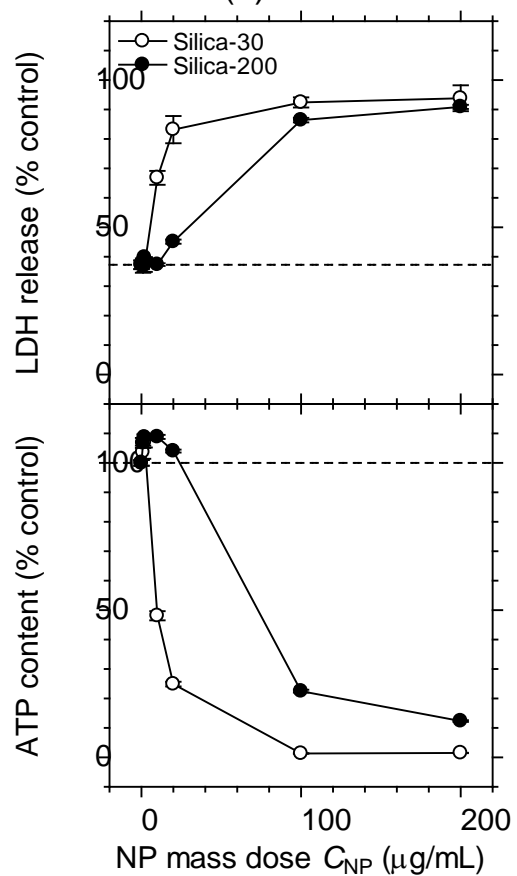

(b) B16F10

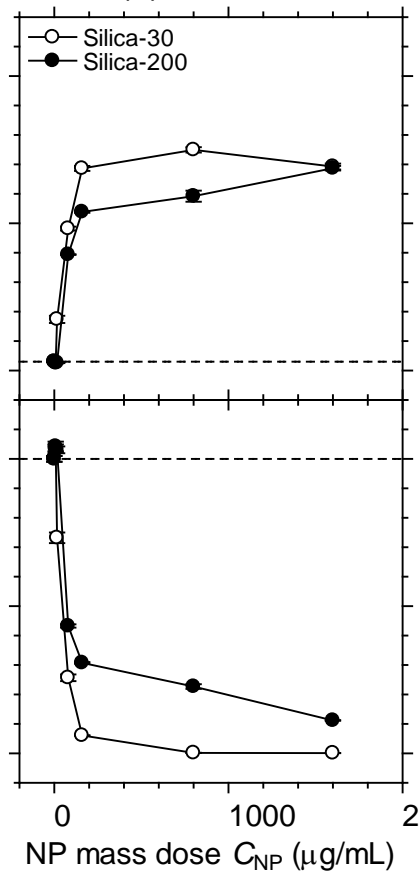

(c) 3774.1

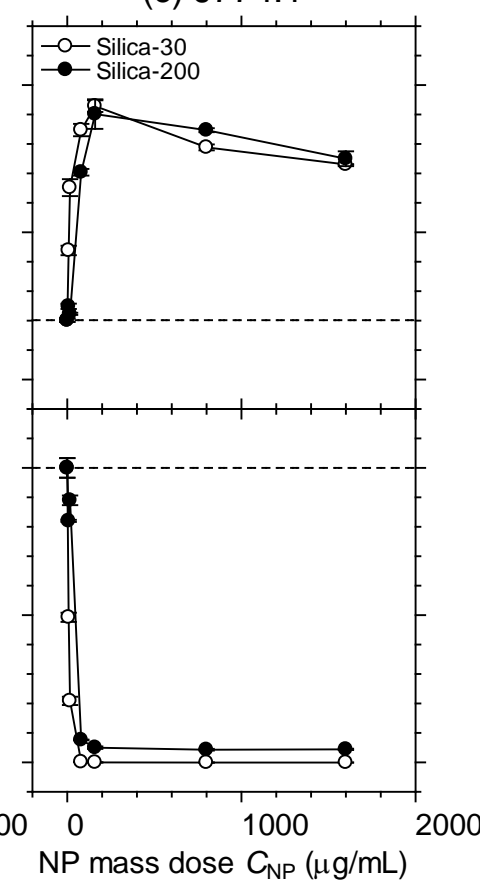

Fig. 1S. LDH release (upper panels) and ATP content (lower panels) of three different cells as a function of NP mass dose, $C_{\text {NP, }}$ after 24-hours exposure to Silica-30 and -200 NPs (see Table 2): (a) Jurkat, (b) B16F10, and (c) J774.1. The dashed lines in upper and lower panels represent the percentages of LDH release and ATP content in the NP-free medium, respectively. The collected data of these assays were expressed as the mean \pm standard error of mean. 
(a) Jurkat

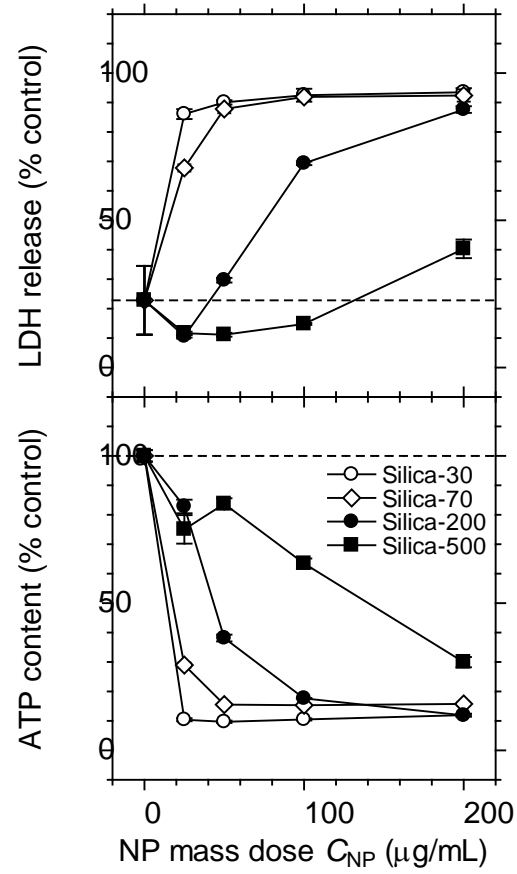

(b) B16F10

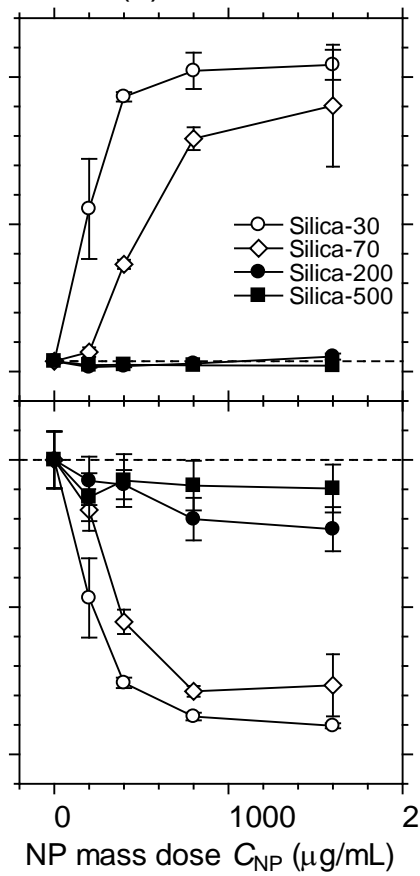

(c) $\mathrm{J774.1}$

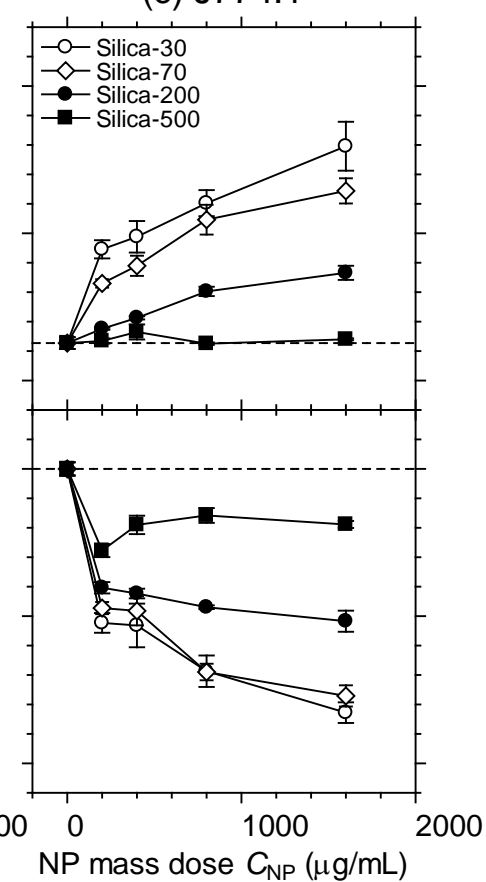

Fig. 2S. LDH release (upper panels) and ATP content (lower panels) of three different cells as a function of NP mass dose, $C_{N P}$, after 2-hours exposure to Silica-30, -70, -200, and -500 NPs (see Table 2): (a) Jurkat, (b) B16F10, and (c) J774.1. The dashed lines in upper and lower panels represent the percentages of LDH release and ATP content in the NP-free medium, respectively. The collected data of these assays were expressed as the mean \pm standard error of mean. 